Research Article

\title{
Convex Sweeping Processes with Noncompact Perturbations and with Delay in Banach Spaces
}

\author{
A. G. Ibrahim and F. Aladsani \\ Department of Mathematics, Faculty of Science, King Faisal University, Al-Ahsa 31982, Saudi Arabia \\ Correspondence should be addressed to A. G. Ibrahim; agamal@kfu.edu.sa \\ Received 13 September 2015; Accepted 20 September 2015 \\ Academic Editor: Khalil Ezzinbi
}

Copyright ( 2016 A. G. Ibrahim and F. Aladsani. This is an open access article distributed under the Creative Commons Attribution License, which permits unrestricted use, distribution, and reproduction in any medium, provided the original work is properly cited.

\begin{abstract}
We prove two results concerning the existence of solutions for functional differential inclusions that are governed by sweeping processes, with noncompact valued perturbations in Banach spaces. Indeed, we have two goals. The first is to give a technique that allows considering sweeping processes with noncompact valued perturbations and associated with a multivalued function depending on time. The second is to give a technique to overcome the arising problem from the nonlinearity of the normalized mappings, when we deal with sweeping processes with noncompact valued perturbations and associated with a multivalued function depending on time and state.
\end{abstract}

\section{Introduction}

In his leading paper, Moreau [1] proposed and studied the following differential inclusion governed by sweeping process of first order:

$$
\begin{aligned}
-u^{\prime}(t) & \in N_{G(t)}(u(t)) \quad \text { a.e. on } I=[0, T], \\
u(0) & =u_{0},
\end{aligned}
$$

where $G$ is a multifunction from the interval $I=[0, T]$ to the family of nonempty closed convex subsets of a Hilbert space $H$ and $N_{G(t)}(u(t))$ is the normal cone of the subset $G(t)$ at the point $u(t)$. Problem (1) corresponds to several important mechanical problems. For more details concerning the applications of (1), we refer to [1].

Since then, important improvements have been developed by several authors. For some existence results of solutions for sweeping processes in Hilbert or Banach spaces, we refer to [2-10].

Let $E$ be a Banach space, $r$ a positive real number, $C_{r}=C_{E}([-r, 0])$ the Banach space of continuous functions from $[-r, 0]$ to $E$ endowed with the uniform norm $\|u\|_{\infty}=$ $\operatorname{Sup}\{\|u(t)\|: t \in[-r, 0]\}, C$ a multifunction from $I$ to the family of nonempty closed convex subsets of $E, F$ a multifunction defined on $I \times C_{r}$ and with nonempty closed values in the topological dual space, $E^{*}$, of $E$, and $\Gamma$ a multifunction from $I \times E^{*}$ to the family of nonempty closed convex subsets of $E$. Let $J: E \rightarrow E^{*}$ and $J^{*}: E^{*} \rightarrow E$ be the normalized duality mappings and for each $t \in I$, $\tau(t): C_{E}([-r, t]) \rightarrow C_{r}$ and $(\tau(t) g)(s)=g(s+t), \forall s \in[-r, 0]$. Let $\Psi \in C_{r}$ be given.

In this paper, we prove two existence results. In the first result (Theorem 15), we prove, in $p$-uniformly convex and $q$ uniformly smooth Banach space, the existence of solutions for the following sweeping process with noncompact valued perturbation and with delay:

$$
\begin{aligned}
u(t) & =\Psi(t), \quad \text { for } t \in[-r, 0] ; \\
u(t) & =\Psi(0)+\int_{0}^{t} u^{\prime}(s) d s, \quad \text { for } t \in I, \\
u(t) & \in C(t), \quad \text { for } t \in I, \\
u^{*}(t) & =J(u(t)), \quad \text { for } t \in I, \\
\left(u^{*}\right)^{\prime}(t) & \in-N_{C(t)}(u(t))+F(t, \tau(t) u),
\end{aligned}
$$

a.e. for $t \in I$. 
In the second result (Theorem 16), we prove, in $p$ uniformly convex and $q$-uniformly smooth Banach spaces, the existence of solutions for the following sweeping process with a noncompact valued perturbation and with delay:

$$
\begin{aligned}
u(t) & =\Psi(t), \quad \text { for } t \in[-r, 0] \\
u(t) & =\Psi(0)+\int_{0}^{t} u^{\prime}(s) d s, \quad \text { for } t \in I, \\
u^{*}(t) & =J^{*}(u(t)), \quad \text { for } t \in I, \\
u(t) & \in \Gamma\left(t, u^{*}(t)\right), \quad \text { for } t \in I, \\
\left(u^{*}\right)^{\prime}(t) & \in-N_{\Gamma\left(t, u^{*}(t)\right)}(u(t))+F(t, \tau(t) u),
\end{aligned}
$$$$
\text { a.e. for } t \in I \text {. }
$$

We prove the existence of solutions for (3) without imposing that the values of $\Gamma$ are contained in a fixed convex compact subset; instead, we suppose that $\Gamma$ satisfies a condition in terms of the Hausdorff measure of noncompactness.

It is important to note that when the sweeping process is associated with a multifunction depending on time and state, the nonlinearity of the normalized duality mappings causes a difficulty when we deal with sweeping process with a perturbation; see, for example, the remark which has been given by Bounkhel and Castaing [6]. For this reason we define the multifunction $\Gamma$ on $I \times E^{*}$.

In order to explain the mathematical motivation for this work, we mention some recent results in this domain.

Aitalioubrahim [2] considered (2) when $X$ is a Hilbert space and the value of $C$ is nonempty compact and not necessarily convex.

In Theorem (4.3) in [5], Bounkhel and Al-Yusof established the existence of solutions for (2), in a separable, $p$ uniformly convex $(p>1)$ and $q$-uniformly smooth $(q>1)$ Banach space without delay and when $J(C(t)) \subseteq G$, for any $t \in I$, for some convex compact set $G \subseteq E^{*} ; F$ is upper semicontinuous with convex compact values and $F(t, x) \subseteq Z$, $\forall(t, x) \in I \times E$, for some convex compact subset $Z \subset E^{*}$.

In Theorem (4.5) in [6], Bounkhel and Castaing considered (3) in a separable, $p$-uniformly convex $(p \geq 2)$ and $q$ uniformly smooth Banach space, $q \in(1,2]$, and when $F=0$ and $\Gamma$ is defined from $I \times E$ to the family of nonempty closed convex subsets of $E$ and satisfies a condition in terms of the Hausdorff measure of noncompactness.

Castaing et al. [10] considered a second-order sweeping process without delay in a separable Hilbert space $H$ in the case when $K$ is a Lipschitz multifunction defined on $I \times H$ and taking closed $\rho$-proxy regular $(\rho>0)$ values in $H$; and $F$ is a convex weakly compact valued scalary upper semicontinuous defined on $I \times H \times H$.

Ibrahim and AL-Adsani [7] considered a second order sweeping process with delay in a separable $p$-uniformly convex and $q$-uniformly smooth Banach space $X$ and the values of perturbation $F$ are nonempty convex weakly compact.

Noel and Thibault [8] established the existence of solutions for nonconvex sweeping processes with a moving set depending on the state in Hilbert spaces.
For other contributions on differential inclusions, see Gomaa [11].

We note that if $E$ is a Hilbert space, then $J$ is equal to the identity mapping, $E$ is 2-uniformly convex and 2uniformly smooth Banach space. Therefore, our technique allows discussing some sweeping process problems with noncompact perturbation in Hilbert spaces or in Banach spaces, whether the moving set depends on time or on time and state.

The paper is organized as follows. Section 2 is devoted to some definitions and notations needed later. In Section 3, we prove the existence of solutions for (2). In Section 4, we give existence of solutions for (3).

\section{Preliminaries and Notations}

Let $P_{c}(E)=\{A \subseteq E: A$ is nonempty closed $\}, P_{c c}(E)=\{A \subseteq$ $E: A$ is nonempty closed convex $\}$, and $P_{c k}(E)=\{A \subseteq E: A$ is nonempty, convex and compact $\}$. Let $B=\{x \in E:\|x\| \leq 1\}$ and $B_{*}=\left\{z \in E^{*}:\|z\| \leq 1\right\}$.

Definition 1 (see Def. 2.4.1 [12]). The multivalued mappings

$$
\begin{aligned}
& J: E \longrightarrow 2^{E^{*}}, \\
& J(x)=\left\{y \in E^{*}:\langle x, y\rangle=\|x\|^{2}=\|y\|^{2}\right\}, \\
& J^{*}: E^{*} \longrightarrow 2^{E}, \\
& J^{*}(y)=\left\{x \in X:\langle y, x\rangle=\|x\|^{2}=\|y\|^{2}\right\}
\end{aligned}
$$

are called the normalized duality mappings.

In the following Lemma, we recall some properties of $J$ and $J^{*}$.

Lemma 2 (see [12], Prop. 2.4.5, 2.4.12, and 2.4.15). We have the following:

(1) If $E$ is a Hilbert space, then $J(x)=\{x\}$, for all $x \in H$.

(2) For each $x \in E, J(x)$ is nonempty closed convex and bounded subset of $E^{*}$.

(3) $J(\lambda x)=\lambda J(x)$, for all $x \in E$ and all $\lambda \in \mathbb{R}$.

(4) If $E^{*}$ is strictly convex, $J$ is single-valued.

(5) If $E$ is strictly convex, $J$ is one to one; that is, $x \neq y \Rightarrow$ $J(x) \cap J(y)=\phi$.

(6) If $E^{*}$ is uniformly convex, then $J$ is uniformly continuous on each bounded set in $E$; that is, $\forall \varepsilon>0$ and $\alpha>0$ there is a $\delta=\delta(\varepsilon, \alpha)>0$ such that for $x$ and $y$ with $\|x\|<\alpha$ and $\|y\|<\alpha$ we have

$$
\begin{aligned}
\|x-y\| & <\delta \Longrightarrow \\
\|J(x)-J(y)\| & <\varepsilon
\end{aligned}
$$

(note that if $E^{*}$ is uniformly convex, then it is strictly convex and hence $J$ is single-valued mapping). 
(7) If $E$ is reflexive, then $J$ is a mapping from $E$ onto $E^{*}$, that is

$$
\cup\{J(x): x \in E\}=E^{*}
$$

(8) If $E$ is reflexive strictly convex space with strictly convex conjugate space $E^{*}$, then $J$ and $J^{*}$ are one-to-one, onto and single-valued mapping and

$$
\begin{aligned}
& J^{-1}=J^{*}, \\
& J J^{*}=I_{X^{*}}, \\
& J^{*} J=I_{X},
\end{aligned}
$$

where $I_{X}$ is the identity mapping on $E$ and $I_{E^{*}}$ is the identity mapping on $E^{*}$. [12-14].

For more properties of the duality mapping, we refer to

Definition 3 (see [12], Def. 2.8.1). The Banach space $E$ is said to be uniformly smooth if

$$
\rho_{E}^{\prime}(0)=\lim _{t \rightarrow 0} \frac{\rho_{E}(t)}{t}=0,
$$

where $\rho_{E}$ is the modulus of smoothness of $E$.

Definition 4 (see [12-14]). Let $q>1$ be a real number. A Banach space $E$ is said to be $q$-uniformly smooth if there exists a constant $c>0$ such that $\rho_{E}(t) \leq c t^{q}, \forall t>0$.

Clearly, every $q$-uniformly smooth Banach space is uniformly smooth.

Lemma 5 (see [12-14]). The following properties are satisfied:

(1) $E$ is uniformly smooth if and only if $E^{*}$ is uniformly convex.

(2) $E$ is uniformly convex if and only if $E^{*}$ is uniformly smooth.

(3) If $E$ is uniformly smooth, then $E$ is reflexive.

Lemma 6 (see $[12,13])$. Let $p>1$ :

(1) If $E$ is $p$-uniformly convex, then $E^{*}$ is $p^{\prime}$-uniformly smooth where $p^{\prime}=p /(p-1)$.

(2) If $E$ is p-uniformly smooth, then $E^{*}$ is $p^{\prime}$-uniformly convex where $p^{\prime}=p /(p-1)$.

Remark 7. It is known that

(1) the Banach space $L^{p}(I, \mathbb{R})$ is $\min \{2, p\}$ uniformly smooth;

(2) if $1<p<2$, then $L^{p}(I, \mathbb{R})$ is 2-uniformly convex; if $2 \leq p$, then $L^{p}(I, \mathbb{R})$ is $p$-uniformly convex.

Now, let

$$
\begin{gathered}
V: E^{*} \times E \longrightarrow \mathbb{R}, \\
V_{*}: E \times E^{*} \longrightarrow \mathbb{R}
\end{gathered}
$$

be two functions defined by

$$
\begin{aligned}
V(\varphi, x) & =\|\varphi\|^{2}-2\langle\varphi, x\rangle+\|x\|^{2}, \\
V_{*}(x, \varphi) & =V(\varphi, x) .
\end{aligned}
$$

Observe that $V(J(x), x)=0, \forall x \in E$, and if $E$ is a Hilbert space, then $V(\varphi, x)=\|\varphi-x\|^{2}$.

Definition 8 (see [12]). Let $Z$ be a nonempty subset of $E$ and $\varphi \in E^{*}$. If there exists a point $z \in Z$ satisfying $V(\varphi, z)=$ $d_{Z}^{V}(\varphi)$, then $z$ is called a generalized projection of $\varphi$ onto $Z$, where $d_{Z}^{V}(\varphi)=\inf _{x \in Z} V(\varphi, x)$.

The set of all such points is denoted by $\pi_{Z}(\varphi)$; that is,

$$
\pi_{Z}(\varphi)=\left\{z \in Z: V(\varphi, z)=d_{Z}^{V}(\varphi)\right\}
$$

The following lemma summarizes some important properties of $V$ and $\pi_{Z}(\varphi)$ (see [12]).

Lemma 9. Let $X$ be a reflexive Banach space with dual space $X^{*}$ and let $Z$ be a nonempty closed convex subset of $X$. The following properties hold:

(1) $\pi_{Z}(\varphi) \neq \phi, \forall \varphi \in X^{*}$.

(2) If $X$ is uniformly convex or uniformly smooth, then

$$
\begin{aligned}
V(\varphi, x) & =0 \Longleftrightarrow \\
\varphi & =J(x),
\end{aligned}
$$

$\forall x \in X, \varphi \in X^{*}$.

(3) $X$ is strictly convex if and only if $\pi_{Z}(\varphi)$ is singleton for all $\varphi \in X^{*}$.

(4) If $X$ is also smooth, then, for any given $\varphi \in X^{*}$,

$$
\begin{aligned}
z & \in \pi_{Z}(\varphi) \Longleftrightarrow \\
\langle\varphi-J(z), x-z\rangle \leq 0, &
\end{aligned}
$$

$\forall x \in X$.

Definition 10 (see $[4,14])$. Let $Z$ be a nonempty closed convex subset of $E$ and $z \in Z$. The convex normal cone of $Z$ at $z$ is defined by

$$
N_{Z}(z)=\left\{\varphi \in E^{*}:\langle\varphi, x-z\rangle \leq 0, \forall x \in E\right\} .
$$

The following lemma gives a closedness property of the subdifferential of the distance function associated with a setvalued mapping with closed convex values.

Lemma 11 (see [14]). Let $Z$ be a nonempty, closed, and convex subset of a Banach space $X$ and $z \in Z$. Then,

(1) $N_{Z}(z) \cap\left\{y \in X^{*}:\|y\| \leq 1\right\}=\partial d_{Z}(z)$, where $\partial d_{Z}(z)$ is the subdifferential of the distance function; 
(2) if $X$ is reflexive and smooth, then

$$
\begin{array}{r}
z \in \pi_{Z}(\varphi) \Longleftrightarrow \\
\varphi-J(z) \in N_{Z}(z),
\end{array}
$$

$$
\forall \varphi \in X^{*}, \forall z \in Z
$$

Let us recall the following lemmas that will be used in the sequel.

Lemma 12 (see [5], Lemma 4.1 and Prop. 4.2). Let $p, q>1$, let $X$ be a p-uniformly convex and $q$-uniformly smooth Banach space, and let $Z$ be a nonempty bounded subset of $X$; then, there exist two constants $a>0$ and $b>0$ such that

$$
\begin{gathered}
a\|x-y\|^{p} \leq V(J(x), y) \leq b\|x-y\|^{q}, \quad \forall x, y \in Z, \\
d_{Z}^{V}(\varphi) \leq b\left(d_{Z}\left(J^{*}(\varphi)\right)\right)^{q}, \quad \forall \varphi \in X^{*} .
\end{gathered}
$$

Moreover, if $Z$, in addition, is closed and $\varphi \in X^{*}$, then

$$
\begin{gathered}
d_{Z}^{V}(\varphi)=0 \Longleftrightarrow \\
J^{*}(\varphi) \in Z .
\end{gathered}
$$

Lemma 13 (see [6], Prop. 4.3). Let $p \geq 2$, and let $X$ be a $p$ uniformly convex and q-uniformly smooth Banach space. The normalized duality mapping J is Lipschitz on bounded sets; that is, for any $R>0$, there is a positive constant dependent on $R, C(R)$, such that

$$
\begin{aligned}
\|x\| & \leq R, \\
\|y\| & \leq R \Longrightarrow \\
\|J(x)-J(y)\| & \leq C(R)\|x-y\| .
\end{aligned}
$$

Lemma 14 (see [15], Lemma 2.3). Let $X$ be a separable Banach space, let $G:[a, b] \rightarrow 2^{X}$ be a measurable multifunction, and let $z:[a, b] \rightarrow X$ be a measurable function. Then, for any positive measurable function $r:[a, b] \rightarrow \mathbb{R}^{+}$, there exists $a$ measurable selection $g$ of $G$ such that for almost all $t \in[a, b]$

$$
\|g(t)-z(t)\| \leq d(z(t), G(t))+r(t) .
$$

\section{Existence Results of Solutions for Problem (2)}

Theorem 15. Let $p>1, q \in(1,2], E$ be a separable, $p$ uniformly convex and q-uniformly smooth Banach space, $C$ : $I \rightarrow P_{c k}(E)$ and $F: I \times C_{r} \rightarrow P_{c}\left(E^{*}\right)$. Suppose that the following conditions hold:

$\left(H_{1}\right)$ There is a convex compact subset $K \subseteq E^{*}$, such that $J(C(t)) \subseteq K, \forall t \in I$.

$\left(H_{2}\right)$ There are two constants $\lambda_{1}$ and $\lambda_{2}$ such that for any $t_{1}$, $t_{2} \in I$ and any $x_{1}, x_{2} \in E$ we have

$$
\begin{gathered}
\left\|\left[d_{C\left(t_{1}\right)}\left(x_{1}\right)\right]^{q / q^{\prime}}-\left[d_{C\left(t_{2}\right)}\left(x_{2}\right)\right]^{q / q^{\prime}}\right\| \\
\leq \lambda_{1}\left|t_{1}-t_{2}\right|+\lambda_{2}\left\|x_{1}-x_{2}\right\|,
\end{gathered}
$$

where $q^{\prime}=q /(q-1)$.
$\left(\mathrm{H}_{3}\right)$ There is a continuous function $m: I \rightarrow R^{\geq 0}$ such that, for any $t, s \in I$ and $\psi_{1}, \psi_{2} \in C_{r}$,

$$
h\left(F\left(t, \psi_{1}\right), F\left(s, \psi_{2}\right)\right) \leq|m(t)-m(s)|+\left\|\psi_{1}-\psi_{2}\right\| .
$$

$\left(H_{4}\right)$ There is a continuous function $P: I \rightarrow R^{\geq 0}$ such that, for any $\varphi \in C_{r}$ and any $t \in I$,

$$
\sup \{\|y\|: y \in F(t, \varphi)\} \leq P(t)(1+\|\varphi(0)\|) \text {, a.e. }
$$

Then, for any fixed $\Psi \in C_{r}$ with $\Psi(0) \in C(0)$, there is a continuous function $u:[-r, T] \rightarrow E$ such that $u$ is Lipschitz on $I$ and satisfies (2).

Proof. Since $E$ is uniformly convex, it is reflexive and strictly convex. Moreover, because $E$ is uniformly smooth, its topological conjugate $E^{*}$ is uniformly convex and hence $E^{*}$ is strictly convex. Then, by property (8) in Lemma 2, the normalized duality maps $J$ and $J^{\prime}$ are one-to-one, onto, single-valued maps and $J J^{*}=I_{E^{*}}, J^{*} J=I_{E}$, where $I_{E^{*}}$ and $I_{E}$ are the identity maps on $E^{*}$ and $E$, respectively. Moreover, since $E$ is reflexive and strictly convex, Lemma 9 ensures that the generalized projection $\pi_{Z}(\varphi)$ is singleton for any closed convex subset $Z$ of $E$ and for any $\varphi \in E^{*}$. Finally, from the reflexivity and smoothness of $E$, Lemma 11 tells us that

$$
\begin{array}{r}
y \in \pi_{Z}(\varphi) \Longleftrightarrow \\
\varphi-J(y) \in N_{Z}(y) .
\end{array}
$$

Now, for any fixed natural number $n \geq 2$, we consider the following partition for $I: t_{i}^{n}=i T / 2^{n}, i=0,1,2, \ldots, 2^{n}$. We put $I_{0}^{n}=\left[t_{0}^{n}, t_{1}^{n}\right], I_{i}^{n}=\left(t_{i}^{n}, t_{i+1}^{n}\right], i=0,1,2, \ldots, 2^{n}-1$, and $\mu_{n}=T / 2^{n}$. Also, let $\theta_{n}, \delta_{n}: I \rightarrow I$ be defined as $\theta_{n}(0)=0$, $\theta_{n}(t)=t_{i+1}^{n}, t \in\left(t_{i}^{n}, t_{i+1}^{n}\right], i=0,1,2, \ldots, 2^{n}-1, \delta_{n}(t)=t_{i}^{n}$, $t \in\left[t_{i}^{n}, t_{i+1}^{n}\right), i=0,1,2, \ldots, 2^{n}-1$, and $\delta_{n}(T)=T$. In order to make the proof easy for the reader, we divide the rest of the proof into steps.

Step 1. In this step, we show that if $n \geq 2$ is a fixed natural number and $z \in L^{1}\left(I, E^{*}\right)$ is a fixed function, then there are $u_{n} \in C([-r, T], E), u_{n}^{*} \in C\left([-r, T], E^{*}\right)$, and $g_{n} \in L^{1}\left(I, E^{*}\right)$ such that $u_{n}$ and $u_{n}^{*}$ are absolutely continuous on $I$ and the following properties hold:

(i) $u_{n}^{*}(t)=J(\Psi(t)), \quad t \in[-r, 0]$;

(ii) $u_{n}(t)=J^{*}\left(u_{n}^{*}(t)\right), \quad t \in[-r, T]$;

(iii) $u_{n}\left(\theta_{n}(t)\right) \in C\left(\theta_{n}(t)\right), \quad t \in I$;

(iv) $g_{n}(t) \in F\left(t, \tau\left(\delta_{n}(t)\right) u_{n}\right), \quad t \in I$;

(v) $\left\|g_{n}(t)-z(t)\right\|$

$$
\leq d\left(z(t), F\left(t, \tau\left(\delta_{n}(t)\right) u_{n}\right)\right)+\frac{1}{n^{2}}, \quad t \in I ;
$$

(vi) $-\left(u_{n}^{*}\right)^{\prime}(t)+g_{n}(t) \in N_{C\left(\theta_{n}(t)\right)}\left(u_{n}\left(\theta_{n}(t)\right)\right)$,

a.e. $t \in I$. 
Indeed, in view of Lemma 14 , there is $g_{0}^{n} \in L^{1}\left(\left[t_{0}^{n}, t_{1}^{n}\right], E^{*}\right)$ such that $g_{0}^{n}(t) \in F(t, \tau(0) \Psi), t \in\left[t_{0}^{n}, t_{1}^{n}\right]$ and

$$
\begin{aligned}
& \left\|g_{0}^{n}(t)-z(t)\right\| \leq d(z(t), F(t, \tau(0) \Psi))+\frac{1}{n^{2}}, \\
& \text { for a.e. } t \in\left[t_{0}^{n}, t_{1}^{n}\right] .
\end{aligned}
$$

Put $x_{0}^{n}=\psi(0)$ and

$$
x_{1}^{n}=\Pi_{C\left(t_{1}^{n}\right)}\left(J\left(x_{0}^{n}\right)+\mu_{n} g_{0}^{n}\left(t_{0}^{n}\right)\right) .
$$

Next, we define $u_{n}^{*}(t)=J(\Psi(t))$ for $t \in[-r, 0]$ and

$$
u_{n}^{*}(t)=\frac{t_{1}^{n}-t}{\mu_{n}} J\left(x_{0}^{n}\right)+\frac{t-t_{0}^{n}}{\mu_{n}} J\left(x_{1}^{n}\right), \quad t \in\left[t_{0}^{n}, t_{1}^{n}\right] .
$$

Observe that, according to Lemma 9, this construction is well defined. Moreover, from the definition of the generalized projection, relation (26) gives us

$$
\frac{J\left(x_{0}^{n}\right)+\mu_{n} g_{0}^{n}\left(t_{0}^{n}\right)-J\left(x_{1}^{n}\right)}{\mu_{n}} \in N_{C\left(t_{1}^{n}\right)}\left(x_{1}^{n}\right)
$$

and this relation together with (27) implies

$$
\begin{array}{r}
-\left(u_{n}^{*}\right)^{\prime}(t)+g_{0}^{n}\left(t_{0}^{n}\right) \in N_{C\left(t_{1}^{n}\right)}\left(x_{1}^{n}\right), \\
\text { a.e. for } t \in\left[t_{0}^{n}, t_{1}^{n}\right] .
\end{array}
$$

Next, by induction, we can define for $i=1,2, \ldots, 2^{n}-1$

$$
\begin{aligned}
u_{n}^{*}(t)=\frac{t_{i+1}^{n}-t}{\mu_{n}} J\left(x_{i}^{n}\right)+\frac{t-t_{i}^{n}}{\mu_{n}} J\left(x_{i+1}^{n}\right), & \\
& t \in\left[t_{i}^{n}, t_{i+1}^{n}\right],
\end{aligned}
$$

where

$$
\begin{aligned}
& x_{i+1}^{n}=\Pi_{C\left(t_{i+1}^{n}\right)}\left(J\left(x_{i}^{n}\right)+\mu_{n} g_{i}^{n}\left(t_{i}^{n}\right)\right), \\
& g_{i}^{n} \in L^{1}\left(\left[t_{i}^{n}, t_{i+1}^{n}\right], E^{*}\right), \\
& g_{i}^{n}(t) \in F\left(t, \tau\left(\delta_{n}(t)\right) u_{n}\right), \quad t \in\left[t_{i}^{n}, t_{i+1}^{n}\right], \\
& u_{n}(t)=J^{*}\left(u_{n}^{*}(t)\right), \quad t \in[-r, T], \\
&\left\|g_{i}^{n}(t)-z(t)\right\| \leq d\left(z(t), F\left(t, \tau\left(\delta_{n}(t)\right) u_{n}\right)\right)+\frac{1}{n^{2}}, \\
& \text { a.e. } t \in\left[t_{i}^{n}, t_{i+1}^{n}\right] .
\end{aligned}
$$

Now, let $g_{n}: I \rightarrow E^{*}$ be such that $g_{n}(t)=g_{i}^{n}(t), t \in$ $\left[t_{i}^{n}, t_{i+1}^{n}\right), i=0,1,2, \ldots, 2^{n}-1$, and $g_{n}(T)=g_{2^{n}}^{n}(T)$. Note that $g_{i}^{n}\left(t_{i}^{n}\right)=g_{i}^{n}\left(\delta_{n}(t)\right)=g_{n}\left(\delta_{n}(t)\right)$, for $t \in\left[t_{i}^{n}, t_{i+1}^{n}\right)$. Therefore, the functions $u_{n}^{*}, g_{n}$, and $u_{n}$ satisfy properties (i)-(vi) in (24).

Step 2. In this step, we show that there are three sequences $\left(u_{n}\right)_{n \geq 2} \subseteq C([-r, T], E),\left(u_{n}^{*}\right)_{n \geq 2} \subseteq C\left([-r, T], E^{*}\right)$, and $\left(g_{n}\right)_{n \geq 2} \subseteq L^{1}\left(I, E^{*}\right)$ such that $u_{n}$ and $u_{n}^{*}$ are absolutely continuous on $[0, T]$ and for any $n \geq 2$ we have

$$
\begin{aligned}
& \text { (i) } u_{n}^{*}(t)=J(\Psi(t)), \quad t \in[-r, 0] \\
& \text { (ii) } u_{n}(t)=J^{*}\left(u_{n}^{*}(t)\right), \quad t \in[-r, T] \\
& \text { (iii) } u_{n}\left(\theta_{n}(t)\right) \in C\left(\theta_{n}(t)\right), \quad t \in I \\
& \text { (iv) } g_{n}(t) \in F\left(t, \tau\left(\delta_{n}(t)\right) u_{n}\right), \quad t \in I \\
& \text { (v) }\left\|g_{n+1}(t)-g_{n}(t)\right\| \\
& \quad \leq d\left(g_{n}(t), F\left(t, \tau\left(\delta_{n+1}(t)\right) u_{n+1}\right)\right)+\frac{1}{(n+1)^{2}},
\end{aligned}
$$$$
\text { a.e. } t \in I \text {; }
$$

(vi) $-\left(u_{n}^{*}\right)^{\prime}(t)+g_{n}(t) \in N_{C\left(\theta_{n}(t)\right)}\left(u_{n}\left(\theta_{n}(t)\right)\right)$,

a.e. $t \in I$.

Indeed, let $z$ be any fixed element in $L^{1}\left(I, E^{*}\right)$; in view of Step 1, there are $u_{2} \in C([-r, T], E), u_{2}^{*} \in C\left([-r, T], E^{*}\right)$, and $g_{2} \in L^{1}\left(I, E^{*}\right)$ such that $u_{2}, u_{2}^{*}$ are absolutely continuous on $[0, T]$ and properties (i) $-(\mathrm{vi})$ in (24) are satisfied for $n=2$. Now, since $g_{2} \in L^{1}\left(I, E^{*}\right)$, then in view of Step 1 , there are $u_{3} \in C([-r, T], E), u_{3}^{*} \in C\left([-r, T], E^{*}\right)$, and $g_{3} \in L^{1}\left(I, E^{*}\right)$ such that $u_{3}, u_{3}^{*}$ are absolutely continuous on $[0, T]$ and (32) is satisfied at $n=3$. So, we can define inductively three sequences $\left(u_{n}\right)_{n \geq 2} \subseteq C([-r, T], E),\left(u_{n}^{*}\right)_{n \geq 2} \subseteq C\left([-r, T], E^{*}\right)$, and $\left(g_{n}\right)_{n \geq 2} \subseteq L^{1}\left(I, E^{*}\right)$ such that properties (i)-(vi) in (32) are satisfied.

Step 3. In this step, we show that there is a positive number $\eta$ such that for any $n \geq 2$

$$
\left\|\left(u_{n}^{*}\right)^{\prime}(t)\right\| \leq \eta, \quad \text { a.e. for } t \in I \text {. }
$$

Let $n \geq 2$ be a fixed natural number. According to $\left(H_{1}\right)$ and $\left(H_{4}\right)$, for any $t \in I$,

$$
\begin{aligned}
\left\|g_{n}(t)\right\| & \leq P(t)\left\|1+\left(\tau\left(\delta_{n}(t) u_{n}\right)(0)\right)\right\| \\
& =P(t)\left\|1+u_{n}\left(\delta_{n}(t)\right)\right\|=P(t)(1+R) \\
& \leq \max _{t \in I} P(t)(1+R)=\rho,
\end{aligned}
$$

where $R=\max \{\|x\|: x \in K\}$. Then, for every $i=$ $0,1,2, \ldots, 2^{n}-1$,

$$
\begin{gathered}
\left\|J\left(x_{i+1}^{n}\right)\right\| \leq R, \\
\left\|J\left(x_{i}^{n}\right)+\mu_{n} g_{i}^{n}\left(t_{i}^{n}\right)\right\| \leq R+T \rho .
\end{gathered}
$$

Let $B=\{x \in E:\|x\| \leq R+T \rho\}$ and $Z=\left\{z \in E^{*}:\|z\| \leq\right.$ $R+T \rho\}$. Note that $E^{*}$ is $q^{\prime}$-uniformly convex $\left(q^{\prime}=q /(1-q)\right)$ and $p^{\prime}$-uniformly smooth $\left(p^{\prime}=p /(p-1)\right)$. Therefore, in view of Lemma 12 and (35), there exists a positive constant $a$ such that

$$
a\left\|z_{1}-z_{2}\right\|^{q^{\prime}} \leq V_{*}\left(J^{*}\left(z_{1}\right), z_{2}\right), \quad \forall z_{1}, z_{2} \in Z .
$$


Then, for every $i=0,1,2, \ldots, 2^{n}-1$,

$$
\begin{aligned}
& a\left\|J\left(x_{i+1}^{n}\right)-\left(J\left(x_{i}^{n}\right)+\mu_{n} g_{i}^{n}\left(t_{i}^{n}\right)\right)\right\|^{q^{\prime}} \\
& \quad \leq V_{*}\left(J^{*}\left(J\left(x_{i+1}^{n}\right)\right), J\left(x_{i}^{n}\right)+\mu_{n} g_{i}^{n}\left(t_{i}^{n}\right)\right) .
\end{aligned}
$$

Further, since $E$ is $p$-uniformly convex and $q$-uniformly smooth, then, again, by Lemma 12 , there is a positive constant $b$ such that

$$
d_{B}^{V} \varphi \leq b\left[d_{B}\left(J^{*}(\varphi)\right)\right]^{q}, \quad \forall \varphi \in E^{*} .
$$

So, for every $i=0,1,2, \ldots, 2^{n}-1$,

$$
\begin{aligned}
& d_{\Gamma\left(t_{i+1}^{n}\right)}^{V}\left(J\left(x_{i}^{n}\right)+\mu_{n} g_{i}^{n}\left(t_{i}^{n}\right)\right) \\
& \quad \leq b\left[d_{C\left(t_{i+1}^{n}\right)}\left(J^{*}\left(J\left(x_{i}^{n}\right)+\mu_{n} g_{i}^{n}\left(t_{i}^{n}\right)\right)\right)\right]^{q} .
\end{aligned}
$$

This relation together with (37) yields

$$
\begin{aligned}
a \| & \left(x_{i+1}^{n}\right)-\left(J\left(x_{i}^{n}\right)+\mu_{n} g_{i}^{n}\left(t_{i}^{n}\right)\right) \|^{q^{\prime}} \\
& \leq V_{*}\left(J^{*}\left(J\left(x_{i+1}^{n}\right)\right), J\left(x_{i}^{n}\right)+\mu_{n} g_{i}^{n}\left(t_{i}^{n}\right)\right) \\
& =V\left(J\left(x_{i}^{n}\right)+\mu_{n} g_{i}^{n}\left(t_{i}^{n}\right), x_{i+1}^{n}\right) \\
& =d_{C\left(t_{i+1}^{n}\right)}^{V}\left(J\left(x_{i}^{n}\right)+\mu_{n} g_{i}^{n}\left(t_{i}^{n}\right)\right) \\
& \leq b\left[d_{C\left(t_{i+1}^{n}\right)}\left(J^{*}\left(J\left(x_{i}^{n}\right)+\mu_{n} g_{i}^{n}\left(t_{i}^{n}\right)\right)\right)\right]^{q} .
\end{aligned}
$$

According to $\left(\mathrm{H}_{2}\right)$, the last inequality implies

$$
\begin{gathered}
\left\|J\left(x_{i+1}^{n}\right)-\left(J\left(x_{i}^{n}\right)+\mu_{n} g_{i}^{n}\left(t_{i}^{n}\right)\right)\right\| \leq\left(\frac{b}{a}\right)^{1 / q^{\prime}} \\
\cdot\left[d_{C\left(t_{i+1}^{n}\right)}\left(J^{*}\left(J\left(x_{i}^{n}\right)+\mu_{n} g_{i}^{n}\left(t_{i}^{n}\right)\right)\right)\right]^{q / q^{\prime}}=\left(\frac{b}{a}\right)^{1 / q^{\prime}} \\
\cdot\left(\left[d_{C\left(t_{i+1}^{n}\right)}\left(J^{*}\left(J\left(x_{i}^{n}\right)+\mu_{n} g_{i}^{n}\left(t_{i}^{n}\right)\right)\right)\right]^{q / q^{\prime}}\right. \\
\left.-\left[d_{C\left(t_{i}^{n}\right)}\left(J^{*}\left(J\left(x_{i}^{n}\right)\right)\right)\right]^{q / q^{\prime}}\right) \leq\left(\frac{b}{a}\right)^{1 / q^{\prime}}\left[\lambda_{1} \mu_{n}\right. \\
\left.+\lambda_{2}\left\|J^{*}\left(J\left(x_{i}^{n}\right)+\mu_{n} g_{i}^{n}\left(t_{i}^{n}\right)\right)-J^{*}\left(J\left(x_{i}^{n}\right)\right)\right\|\right] .
\end{gathered}
$$

Moreover, from the assumption $q \in(1,2]$, we infer that $q^{\prime} \geq 2$. Then, $E^{*}$ is $q^{\prime}$-uniformly convex $\left(q^{\prime} \geq 2\right)$ and $p^{\prime}$ uniformly smooth. Hence, from Lemma 13 , there is a constant $\beta$, depending on $(2 R+T \rho)$, such that, for all $z_{1}, z_{1} \in E^{*}$, $\left\|z_{1}\right\| \leq 2 R+T \zeta$, and $\left\|z_{1}\right\| \leq 2 R+T \rho$, we have

$$
\left\|J^{*}\left(z_{1}\right)-J^{*}\left(z_{2}\right)\right\| \leq \beta\left\|z_{1}-z_{2}\right\| \text {. }
$$

Consequently,

$$
\begin{aligned}
& \left\|J^{*}\left(J\left(x_{i}^{n}\right)+\mu_{n} g_{i}^{n}\left(t_{i}^{n}\right)\right)-J^{*}\left(J\left(x_{i}^{n}\right)\right)\right\| \\
& \quad \leq \beta\left\|J\left(x_{i}^{n}\right)+\mu_{n} g_{i}^{n}\left(t_{i}^{n}\right)-J\left(x_{i}^{n}\right)\right\|=\beta \mu_{n}\left\|g_{i}^{n}\left(t_{i}^{n}\right)\right\| \\
& \quad=\beta \mu_{n} \rho .
\end{aligned}
$$

This inequality and (41) yield

$$
\begin{gathered}
\left\|J\left(x_{i+1}^{n}\right)-\left(J\left(x_{i}^{n}\right)+\mu_{n} g_{i}^{n}\left(t_{i}^{n}\right)\right)\right\| \\
\leq\left(\frac{b}{a}\right)^{1 / q^{\prime}}\left[\lambda_{1} \mu_{n}+\beta \lambda_{2} \mu_{n} \rho\right] .
\end{gathered}
$$

Thus,

$$
\begin{aligned}
\left\|J\left(x_{i+1}^{n}\right)-J\left(x_{i}^{n}\right)\right\| \leq & \left(\frac{b}{a}\right)^{1 / q^{\prime}}\left[\lambda_{1} \mu_{n}+\beta \lambda_{2} \mu_{n} \rho\right] \\
& +\mu_{n} \rho=\mu_{n}\left(\overline{\lambda_{1}}+\overline{\lambda_{2}}\right),
\end{aligned}
$$

where $\overline{\lambda_{1}}=(b / a)^{1 / q^{\prime}} \lambda_{1}$ and $\overline{\lambda_{2}}=\rho+(b / a)^{1 / q^{\prime}} \beta \rho \lambda_{2}$.

Therefore, for $n \geq 2, i=0,1,2, \ldots, 2^{n}-1$, and $t \in$ $\left(t_{i}^{n}, t_{i+1}^{n}\right)$, we get

$$
\left\|\left(u_{n}^{*}\right)^{\prime}(t)\right\| \leq\left(\overline{\lambda_{1}}+\overline{\lambda_{2}}\right)=\eta
$$

This proves that (33) is true.

Step 4. Our claim in this step is to show that the sequence $\left(u_{n}^{*}\right)_{n \geq 2}$ has a convergent subsequence, still denoted by $\left(u_{n}^{*}\right)_{n \geq 2}$, converging uniformly to a Lipschitz function $u^{*}$ : $I \rightarrow E^{*},\left(u_{n}^{*}\right)_{n \geq 2}^{\prime}$ converges weakly to $\left(u^{*}\right)^{\prime}$, and $\left(u_{n}\right)$ converges uniformly to $u=J^{*}\left(u^{*}\right)$.

Indeed, according to the definition of $u_{n}^{*}$ and (33), the sequence $\left(u_{n}^{*}\right)_{n \geq 2}$ is equicontinuous. Moreover, let $t \in I$. Then, there are $n \geq 2, i=0,1,2, \ldots, 2^{n}-1$, such that $t \in\left[t_{i}^{n}, t_{i+1}^{n}\right]$. Hence, in view of (30) and $\left(H_{1}\right), u_{n}^{*}(t) \in K$. This shows that the set $\left\{u_{n}^{*}(t): n \geq 2\right\}$ is relatively compact in $E^{*}$. Therefore, Theorem 4. Ch.1. in [16] implies that there is a Lipschitz function $u^{*}: I \rightarrow E^{*}$, such that the sequence $\left(u_{n}^{*}\right)_{n \geq 2}$ has a subsequence, still denoted by $\left(u_{n}^{*}\right)_{n \geq 2}$, which converges uniformly to $u^{*}$, and $\left(u_{n}^{*}\right)_{n \geq 2}^{\prime}$ converges weakly to $\left(u^{*}\right)^{\prime}$. We extend the definition of $u^{*}$ on $[-r, T]$ by putting $u^{*}(t)=$ $J(\Psi(t)), t \in[-r, 0]$. Thus, $\left(u_{n}^{*}\right)_{n \geq 2}$ converges uniformly to $u^{*}$ on $[-r, T]$. Since $J^{*}$ is uniformly continuous on the compact set $K$, then the sequence $\left(u_{n}\right)_{n \geq 2}$ is uniformly convergent to $u:[-r, T] \rightarrow E$ with $u=J^{*}\left(u^{*}\right)$. This proves our claim in this step.

Step 5. Let us show that $u(t) \in C(t), t \in I$.

Let $t \in I$. According to $\left(\mathrm{H}_{2}\right)$, we have

$$
\begin{aligned}
& {\left[d_{C(t)}(u(t))\right]^{q / q^{\prime}}} \\
& \quad=\left|\left[d_{C(t)}(u(t))\right]^{q / q^{\prime}}-\left[d_{C\left(\theta_{n}(t)\right)}\left(u_{n}\left(\theta_{n}(t)\right)\right)\right]^{q / q^{\prime}}\right| \\
& \quad \leq \lambda_{1}\left|\theta_{n}(t)-t\right|+\lambda_{2}\left\|u(t)-u_{n}\left(\theta_{n}(t)\right)\right\| .
\end{aligned}
$$

Since $\lim _{n \rightarrow \infty} \lambda_{1}\left|\theta_{n}(t)-t\right|+\lambda_{2}\left\|u(t)-u_{n}\left(\theta_{n}(t)\right)\right\|=0$, therefore, $u(t) \in C(t), \forall t \in J$.

Step 6. In this step, we show that $\lim _{n \rightarrow \infty} \| \tau\left(\delta_{n}(t)\right) u_{n}-$ $\tau(t) u \|_{C_{E}([-r, 0])}=0$, for every $t \in I$. 
Let $t \in I$. We have

$$
\begin{aligned}
& \left\|\tau\left(\delta_{n}(t)\right) u_{n}-\tau(t) u\right\|_{C_{E}([-r, 0])} \\
& \leq\left\|\tau\left(\delta_{n}(t)\right) u_{n}-\tau(t) u_{n}\right\|_{C_{E}([-r, 0])} \\
& +\left\|\tau(t) u_{n}-\tau(t) u\right\|_{C_{E}([-r, 0])} \\
& \leq \sup _{-r \leq s \leq 0}\left\|u_{n}\left(\delta_{n}(t)+s\right)-u_{n}(t+s)\right\| \\
& +\left\|\tau(t) u_{n}-\tau(t) u\right\|_{C_{E}([-r, 0])} \\
& \leq \sup _{\substack{-r \leq s_{1} \leq s_{2} \leq 1 \\
\left|s_{1}-s_{2}\right| \leq 1 / n}}\left\|u_{n}\left(s_{1}\right)-u_{n}\left(s_{2}\right)\right\| \\
& +\left\|\tau(t) u_{n}-\tau(t) u\right\|_{C_{E}([-r, 0])} \\
& \leq \sup _{\substack{-r \leq s_{1} \leq s_{2} \leq 0 \\
\left|s_{1}-s_{2}\right| \leq 1 / n}}\left\|u_{n}\left(s_{1}\right)-u_{n}\left(s_{2}\right)\right\| \\
& +\sup _{\substack{-r \leq s_{1} \leq 0 \leq s_{2} \leq 1 \\
\left|s_{1}-s_{2}\right| \leq 1 / n}}\left\|u_{n}\left(s_{1}\right)-u_{n}\left(s_{2}\right)\right\| \\
& +\sup _{\substack{0 \leq s_{1} \leq s_{2} \leq 1 \\
\left|s_{1}-s_{2}\right| \leq 1 / n}}\left\|u_{n}\left(s_{1}\right)-u_{n}\left(s_{2}\right)\right\| \\
& +\left\|\tau(t) u_{n}-\tau(t) u\right\|_{C_{E}([-r, 0])} \\
& \leq \sup _{\substack{-r \leq s_{1} \leq s_{2} \leq 0 \\
\left|s_{1}-s_{2}\right| \leq 1 / n}}\left\|\Psi\left(s_{1}\right)-\Psi\left(s_{2}\right)\right\| \\
& +\sup _{\substack{-r \leq s_{1} \leq 0 \\
\left|s_{1}\right| \leq 1 / n}}\left\|u_{n}\left(s_{1}\right)-u_{n}(0)\right\| \\
& +\sup _{\substack{0 \leq s_{2} \leq 1 \\
\left|s_{2}\right| \leq 1 / n}}\left\|u_{n}(0)-u_{n}\left(s_{2}\right)\right\| \\
& +\sup _{\substack{0 \leq s_{1} \leq s_{2} \leq 1 \\
\left|s_{1}-s_{2}\right| \leq 1 / n}}\left\|u_{n}\left(s_{1}\right)-u_{n}\left(s_{2}\right)\right\| \\
& +\left\|\tau(t) u_{n}-\tau(t) u\right\|_{C_{E}([-r, 0])} \\
& \leq 2 \sup _{\substack{-r \leq s_{1} \leq s_{2} \leq 0 \\
\left|s_{1}-s_{2}\right| \leq 1 / n}}\left\|\Psi\left(s_{1}\right)-\Psi\left(s_{2}\right)\right\| \\
& +2 \sup _{\substack{0 \leq s_{1} \leq s_{2} \leq 1 \\
\left|s_{1}-s_{2}\right| \leq 1 / n}}\left\|u_{n}\left(s_{1}\right)-u_{n}\left(s_{2}\right)\right\| \\
& +\left\|\tau(t) u_{n}-\tau(t) u\right\| .
\end{aligned}
$$

By the continuity of $\Psi$, the uniform convergence of $u_{n}$ towards $u$, and the preceding estimate, we get $\lim _{n \rightarrow \infty}\left\|\tau\left(\delta_{n}(t)\right) u_{n}-\tau(t) u\right\|=0$.

Step 7. In this step, we show that the sequence $\left(f_{n}\right)_{n \geq 2}$, defined by $f_{n}(t)=g_{n}\left(\delta_{n}(t)\right)$, converges almost everywhere to a function $f \in L^{1}\left(I, E^{*}\right)$ and $f(t) \in F(t, \tau(t) u)$, a.e. $t \in I$.
To prove this, let $n \geq 2$ and let $t \in I$ be a fixed point such that (32)(iv) and (v) are satisfied. In view of $\left(H_{4}\right)$, we have

$$
\begin{aligned}
& \left\|f_{n+1}(t)-f_{n}(t)\right\|=\left\|g_{n+1}\left(\delta_{n+1}(t)\right)-g_{n}\left(\delta_{n}(t)\right)\right\| \\
& =d\left(g_{n}\left(\delta_{n}(t)\right),\right. \\
& \left.F\left(\delta_{n+1}(t), \tau\left(\delta_{n+1}\left(\delta_{n+1}(t)\right)\right) u_{n+1}\right)\right)+\frac{1}{(n+1)^{2}} \\
& \quad=d\left(g_{n}\left(\delta_{n}(t)\right), F\left(\delta_{n+1}(t), \tau\left(\delta_{n+1}(t)\right) u_{n+1}\right)\right) \\
& +\frac{1}{(n+1)^{2}}=h\left(F\left(\delta_{n}(t), \tau\left(\delta_{n}\left(\delta_{n}(t)\right)\right) u_{n}\right),\right. \\
& \left.\quad F\left(\delta_{n+1}(t), \tau\left(\delta_{n+1}\left(\delta_{n+1}(t)\right)\right) u_{n+1}\right)\right)+\frac{1}{(n+1)^{2}} \\
& \quad=h\left(F\left(\delta_{n}(t), \tau\left(\delta_{n}(t)\right) u_{n}\right),\right. \\
& \quad-\tau\left(\delta_{n}(t)\right) u_{n} \|+\frac{1}{(n+1)^{2}} . \\
& \quad+\frac{1}{(n+1)^{2}} \leq\left|m\left(\delta_{n+1}(t)\right)-m\left(\delta_{n}(t)\right)\right| \\
& \left.\left.\quad \leq \mid m\left(\delta_{n+1}(t)\right)-\tau\left(\delta_{n+1}(t)\right) u_{n+1}\right)\right)+\frac{1}{(n+1)^{2}} \\
& -
\end{aligned}
$$

Thus, for any two natural numbers $n$ and $q(2<n<q)$, we infer that

$$
\begin{aligned}
& \left\|f_{n}(t)-f_{q}(t)\right\| \\
& =\left\|f_{n}(t)-f_{n+1}(t)\right\|+\left\|f_{n+1}(t)-f_{n+2}(t)\right\|+\cdots \\
& \quad+\left\|f_{q-1}(t)-f_{q}(t)\right\| \\
& \leq\left|m\left(\delta_{n+1}(t)\right)-m\left(\delta_{n}(t)\right)\right| \\
& \quad+\left|m\left(\delta_{n+2}(t)\right)-m\left(\delta_{n+1}(t)\right)\right|+\cdots \\
& \quad+\left|m\left(\delta_{q-1}(t)\right)-m\left(\delta_{q}(t)\right)\right| \\
& \quad+\left\|\tau\left(\delta_{n+1}(t)\right) u_{n+1}-\tau\left(\delta_{n}(t)\right) u_{n}\right\|
\end{aligned}
$$




$$
\begin{aligned}
& \quad+\left\|\tau\left(\delta_{n+2}(t)\right) u_{n+2}-\tau\left(\delta_{n+1}(t)\right) u_{n+1}\right\|+\cdots \\
& +\left\|\tau\left(\delta_{q}(t)\right) u_{q}-\tau\left(\delta_{q-1}(t)\right) u_{q-1}\right\|+\frac{1}{(n+1)^{2}} \\
& +\frac{1}{(n+2)^{2}}+\cdots+\frac{1}{r^{2}} \\
& \leq\left|m\left(\delta_{n+1}(t)\right)-m\left(\delta_{n}(t)\right)\right| \\
& +\left|m\left(\delta_{n+2}(t)\right)-m\left(\delta_{n+1}(t)\right)\right|+\cdots \\
& +\left|m\left(\delta_{q-1}(t)\right)-m\left(\delta_{q}(t)\right)\right| \\
& +\left\|\tau\left(\delta_{n+1}(t)\right) u_{n+1}-\tau\left(\delta_{n}(t)\right) u_{n}\right\| \\
& +\left\|\tau\left(\delta_{n+2}(t)\right) u_{n+2}-\tau\left(\delta_{n+1}(t)\right) u_{n+1}\right\|+\cdots \\
& +\left\|\tau\left(\delta_{q}(t)\right) u_{q}-\tau\left(\delta_{q-1}(t)\right) u_{q-1}\right\|+\frac{r-n}{(n+1)^{2}} .
\end{aligned}
$$

Since $\lim _{n \rightarrow \infty} \delta_{n}(t)=t, m$ is continuous, and $\lim _{n \rightarrow \infty}\left\|\tau\left(\delta_{n}(t)\right) u_{n}-\tau(t) u\right\|_{C_{E}([-r, 0])}=0$, then the right-hand side of the last inequality tends to zero when $n, q \rightarrow \infty$. Hence, the sequence $\left(f_{n}(t)\right)_{n \geq 2}$ is a Cauchy sequence in $E^{*}$. Thus, there is a function $f: I \rightarrow E^{*}$ such that

$$
\lim _{n \rightarrow \infty} f_{n}(t)=f(t), \quad \text { a.e. } t \in I .
$$

Observe that, by (34), $\left\|f_{n}(t)\right\| \leq \rho, \forall t \in I$. So, $f \in L^{1}\left(I, E^{*}\right)$. It remains to show that $f(t) \in F(t, \tau(t) u)$, a.e. $t \in I$. Indeed, for every $n \geq 2$ and almost everywhere $t \in I$, we have

$$
\begin{aligned}
d( & f(t), F(t, \tau(t) u)) \\
\leq & \left\|f(t)-f_{n}(t)\right\|+d\left(f_{n}(t), F(t, \tau(t) u)\right) \\
\leq & \left\|f(t)-f_{n}(t)\right\|+d\left(g_{n}\left(\delta_{n}(t)\right), F(t, \tau(t) u)\right) \\
\leq & \left\|f(t)-f_{n}(t)\right\| \\
& +h\left(F\left(\delta_{n}(t), \tau\left(\delta_{n}(t)\right) u_{n}\right), F(t, \tau(t) u)\right) .
\end{aligned}
$$

This relation and $\left(\mathrm{H}_{4}\right)$ imply

$$
\begin{aligned}
& d(f(t), F(t, \tau(t) u)) \\
& \quad \leq\left\|f(t)-f_{n}(t)\right\|+\left|m\left(\delta_{n}(t)\right)-m(t)\right| \\
& \quad+\left\|\tau\left(\delta_{n}(t)\right) u_{n}-\tau(t) u\right\| .
\end{aligned}
$$

Because $f_{n}$ converges to $f$ almost everywhere, $m$ is continuous, and $\lim _{n \rightarrow \infty}\left\|\tau\left(\delta_{n}(t)\right) u_{n}-\tau(t) u\right\|_{C_{E}([-r, 0])}=0$, for every $t \in I$, we conclude that $f(t) \in F(t, \tau(t) u)$, a.e. $t \in I$.

Step 8 . We proceed to show that

$$
-(J u)^{\prime}(t)+f(t) \in N_{C(t)} u(t), \quad \text { a.e. } t \in I .
$$

We follow the arguments used in [10]. In view of (32)(vi), (37), and Lemma 11, for every natural number $n \geq 2$ one obtains

$$
-\left(J u_{n}\right)^{\prime}(t)+f_{n}(t) \in \lambda \partial d_{C\left(\theta_{n}(t)\right)}\left(u_{n}\left(\theta_{n} t\right)\right), \quad \text { a.e., }
$$

where $\lambda=\eta+\rho .\left(H_{2}\right)$. Observe that the uppersemicontinuity of the subdifferential of Lipschtz function ([17], Prop. 1.7) imply the multivalued function $(t, y) \rightarrow \partial d_{C(t)}(y)$ is scalary uppersemicontinuous with convex and weak ${ }^{*}$ compact values. That is, let $t_{n} \rightarrow t$, in $I, y_{n} \rightarrow y$, in $E, y_{n} \in C\left(t_{n}\right)$, and $y \in C(t)$. Then, for any $v \in E$,

$$
\limsup _{n \rightarrow \infty} \sigma\left(v, \partial d_{C\left(t_{n}\right)}\left(y_{n}\right)\right) \leq \sigma\left(v, \partial d_{C(t)}(y)\right) .
$$

So, for any $v \in E$,

$$
\begin{aligned}
& \limsup _{n \rightarrow \infty} \sigma\left(v, \partial d_{C\left(\theta_{n}(t)\right)}\left(u_{n}\left(\theta_{n} t\right)\right)\right) \\
& \quad \leq \sigma\left(v, \partial d_{C(t)}(u(t))\right),
\end{aligned}
$$

where $\sigma$ is the support function.

Now, let $\left(e_{k}\right)$ be a sequence in $E$ which separates the points. Hence, from the weak convergence of the sequence $\left(\left(J u_{n}\right)^{\prime}+f_{n}\right)_{n \geq 2}$ to $J\left(u^{\prime}\right)+f$ in $L^{1}\left(I, E^{*}\right)$, for any Lebesgue measurable subset $A \subseteq J$, we have

$$
\begin{aligned}
\int_{A} & \left\langle e_{k},\left(-(J u)^{\prime}(t)+f(t)\right)\right\rangle d t \\
& =\lim _{n \rightarrow \infty} \int_{A}\left\langle e_{k},\left(-\left(J u_{n}\right)^{\prime}(t)+f_{n}(t)\right)\right\rangle d t .
\end{aligned}
$$

This relation with (55) and (57) yields

$$
\begin{aligned}
& \int_{A}\left\langle e_{k},\left(-(J u)^{\prime}(t)+f(t)\right)\right\rangle d t \\
& \quad \leq \limsup _{n \rightarrow \infty} \int_{A} \sigma\left(e_{k}, \lambda \partial d_{C\left(\theta_{n}(t)\right)}\left(u_{n}\left(\theta_{n} t\right)\right)\right) d t \\
& \quad \leq \int_{A} \limsup _{n \rightarrow \infty} \sigma\left(e_{k}, \lambda \partial d_{C\left(\theta_{n}(t)\right)}\left(u_{n}\left(\theta_{n} t\right)\right)\right) d t \\
& \quad \leq \int_{A} \sigma\left(e_{k}, \lambda \partial d_{C(t)}(u(t))\right) d t .
\end{aligned}
$$

Therefore,

$$
\begin{aligned}
\left\langle e_{k},\left(-(J u)^{\prime}(t)+f(t)\right)\right\rangle \leq \sigma\left(e_{k}, \lambda \partial d_{C(t)}(u(t))\right), & \\
\forall k & \geq 1 .
\end{aligned}
$$

Again, since the multivalued function $t \rightarrow \partial d_{C}(u(t))$ is measurable with convex and weak ${ }^{*}$ compact, then by ([18], III.35) it follows that

$$
-(J u)^{\prime}(t)+f(t) \in \lambda \partial d_{C(t)}(u(t)), \quad \text { a.e. } t \in I .
$$

As $u(t) \in C(t), \forall t \in I$, we get

$$
-(J u)^{\prime}(t)+f(t) \in N_{C(t)} u^{\prime}(t), \quad \text { a.e. }
$$

This completes the proof. 


\section{Existence Result for (3)}

In the following theorem, we present an existence theorem of solutions for (3). We do not assume that the values of $\Gamma$ are contained in a convex compact fixed subset.

Theorem 16. Let $p \geq 2$, let $q \in(1,2]$, let $E$ be a separable, p-uniformly convex and q-uniformly smooth Banach space, let $T>0$, let $\Gamma: I \times E^{*} \rightarrow P_{c c}(E)$, and let $F: I \times C_{r} \rightarrow P_{c c}\left(E^{*}\right)$. Suppose that $\left(\mathrm{H}_{3}\right),\left(\mathrm{H}_{4}\right)$ and the following conditions hold:

$\left(H_{5}\right)$ There is a positive constant $R$ such that $\Gamma(t, x) \subseteq$ $R B(0,1), \forall(t, x) \in I \times E^{*}$.

$\left(H_{6}\right)$ There are three positive constants $\gamma_{1}, \gamma_{2}, \gamma_{3}$ with $0<$ $\gamma_{2}<(a / b)^{1 / q^{\prime}}$ such that for any $t_{1}, t_{2} \in I$, any $x_{1}, x_{2} \in$ $E$, and any $y_{1}, y_{2} \in E^{*}$ we have

$$
\begin{aligned}
& \left\|\left[d_{\Gamma\left(t_{1}, y_{1}\right)}\left(x_{1}\right)\right]^{q / q^{\prime}}-\left[d_{\Gamma\left(t_{2}, y_{2}\right)}\left(x_{2}\right)\right]^{q / q^{\prime}}\right\| \\
& \quad \leq \gamma_{1}\left|t_{1}-t_{2}\right|+\gamma_{2}\left\|y_{1}-y_{2}\right\|+\gamma_{3}\left\|x_{1}-x_{2}\right\|,
\end{aligned}
$$

where $q^{\prime}=q /(1-q)$ and the coefficients $a, b$ are given in Lemma 12.

$\left(H_{7}\right)$ For any $t \in I$ and any bounded subset $A$ in $E^{*}$ with $\chi_{E^{*}}(A)>0$ and any $r>0$, one has

$$
\chi((\Gamma(t, A)) \cap r B(0,1))<\chi_{E}\left(A^{*}\right),
$$

where $A^{*}=\left\{J^{*}(x): x \in A\right\}$.

Then, for any fixed $\Psi \in C_{r}$ satisfying $\Psi(0) \in$ $\Gamma(0, J(\Psi(0)))$, there is a continuous function $u:[-r, T] \rightarrow E$ such that $u$ is absolutely continuous on $[0, T]$ and

$$
\begin{aligned}
u(t) & =\Psi(t), \quad \text { for } t \in[-r, 0] ; \\
u(t) & =\Psi(0)+\int_{0}^{t} u^{\prime}(s) d s, \quad \text { for } t \in I, \\
u(t) & \in \Gamma(t, J(u(t))), \quad \text { for } t \in I, \\
-\left(J(u)^{\prime}(t)\right) & \in N_{\Gamma(t, J(u(t)))}(u(t))+F(t, \tau(t) u), \text { a.e. }
\end{aligned}
$$

for $t \in I$.

Proof. We divide the proof into the following steps.

Step 1 . For any fixed natural number $n \geq 2$, let $t_{i}^{n}, I_{0}^{n}, I_{i}^{n}, i=$ $0,1,2, \ldots, 2^{n}-1, \mu_{n}, \theta_{n}$, and $\delta_{n}$ be as in the proof of Theorem 15.

By following the same lines in Steps 1 and 2 in the proof of Theorem 15, with the following modifications: $x_{0}^{n}=\Psi(0)$,

$$
\begin{array}{r}
x_{i+1}^{n}=\prod_{\Gamma\left(t_{i+1}^{n}, J\left(x_{i}^{n}\right)\right)}\left(J\left(x_{i}^{n}\right)+\mu_{n} g_{i}^{n}\left(t_{i}^{n}\right)\right), \\
\quad i=1,2, \ldots, 2^{n}-1 ;
\end{array}
$$

$$
\begin{aligned}
& g_{i}^{n} \in L^{1}\left(\left[t_{i}^{n}, t_{i+1}^{n}\right], E^{*}\right) ; \\
& g_{i}^{n}(t) \in F\left(t, \tau\left(\delta_{n}(t)\right) u_{n}\right), \quad t \in\left[t_{i}^{n}, t_{i+1}^{n}\right] ; \\
& u_{n}^{*}(t)=\frac{t_{i+1}^{n}-t}{\mu_{n}} J\left(x_{i}^{n}\right)+\frac{t-t_{i}^{n}}{\mu_{n}} J\left(x_{i+1}^{n}\right), \\
& \quad t \in\left[t_{i}^{n}, t_{i+1}^{n}\right] ; \\
& u_{n}(t)=J^{*}\left(u_{n}^{*}(t)\right), \quad t \in[-r, T],
\end{aligned}
$$

we can show that there are $u_{n} \in C([-r, T], E), u_{n}^{*} \in$ $C\left([-r, T], E^{*}\right)$, and $g_{n} \in L^{1}\left(I, E^{*}\right)$ such that $u_{n}$ and $u_{n}^{*}$ are absolutely continuous on $I$ and the following properties hold:

$$
\begin{aligned}
& \text { (i) } u_{n}(t)=\Psi(t), \quad t \in[-r, 0] \\
& \text { (ii) } u_{n}^{*}(t)=J\left(u_{n}(t)\right), \quad t \in[-r, T] \\
& \text { (iii) } u_{n}\left(\theta_{n}(t)\right) \in \Gamma\left(\theta_{n}(t), u_{n}^{*}\left(\delta_{n}(t)\right)\right), \quad t \in I \\
& \text { (iv) } g_{n}(t) \in F\left(t, \tau\left(\delta_{n}(t)\right) u_{n}\right), \quad t \in I \\
& \text { (v) }\left\|g_{n+1}(t)-g_{n}(t)\right\| \\
& \quad \leq d\left(g_{n}(t), F\left(t, \tau\left(\delta_{n+1}(t)\right) u_{n+1}\right)\right)+\frac{1}{(n+1)^{2}}
\end{aligned}
$$$$
\text { a.e. } t \in I \text {; }
$$

(vi) $-\left(u_{n}^{*}\right)^{\prime}(t)+g_{n}(t) \in N_{\Gamma\left(\theta_{n}(t), u_{n}^{*}\left(\delta_{n}(t)\right)\right)} u_{n}\left(\theta_{n}(t)\right)$, a.e. $t \in I$.

Step 2. In this step, we show that there is a positive number $\eta$ such that, for any $n \geq 2$,

$$
\left\|\left(u_{n}^{*}\right)^{\prime}(t)\right\| \leq \eta, \quad \text { a.e. for } t \in I
$$

Let $n \geq 2$ be a fixed natural number. According to $\left(H_{5}\right)$ and $\left(H_{6}\right)$, for any $t \in I$, we have

$$
\begin{aligned}
\left\|g_{n}(t)\right\| & \leq P(t)\left\|1+\tau\left(\delta_{n}(t) u_{n}\right)(0)\right\| \\
& =P(t)\left\|1+u_{n}\left(\delta_{n}(t)\right)\right\|=P(t)(1+R) \\
& \leq \max _{t \in I} P(t)(1+R)=\zeta .
\end{aligned}
$$

Then, for $i \in\left\{i=0,1,2, \ldots, 2^{n}-1\right\}$,

$$
\begin{aligned}
\left\|J\left(x_{i+1}^{n}\right)\right\| & \leq R, \\
\left\|J\left(x_{i}^{n}\right)+\mu_{n} g_{i}^{n}\left(t_{i}^{n}\right)\right\| & \leq R+T \zeta,
\end{aligned}
$$


Note that $E^{*}$ is $q^{\prime}$-uniformly convex and $p^{\prime}$-uniformly smooth. Therefore, in view of (73), (74), and Lemma 12, there exists a positive constant $a$ such that

$$
\begin{aligned}
& a\left\|J\left(x_{i+1}^{n}\right)-\left(J\left(x_{i}^{n}\right)+\mu_{n} g_{i}^{n}\left(t_{i}^{n}\right)\right)\right\|^{q^{\prime}} \\
& \quad \leq V_{*}\left(J^{*}\left(J\left(x_{i+1}^{n}\right)\right), J\left(x_{i}^{n}\right)+\mu_{n} g_{i}^{n}\left(t_{i}^{n}\right)\right) .
\end{aligned}
$$

In addition, since $E$ is $p$-uniformly convex and $q$ uniformly smooth, then, again, by Lemma 12, there is a positive constant $b$ such that

$$
\begin{aligned}
& d_{\Gamma\left(t_{i+1}^{n}, J\left(x_{i}^{n}\right)\right)}^{V}\left(J\left(x_{i}^{n}\right)+\mu_{n} g_{i}^{n}\left(t_{i}^{n}\right)\right) \\
& \quad \leq b\left[d_{\Gamma\left(t_{i+1}^{n}, J\left(x_{i}^{n}\right)\right)}\left(J^{*}\left(J\left(x_{i}^{n}\right)+\mu_{n} g_{i}^{n}\left(t_{i}^{n}\right)\right)\right)\right]^{q} .
\end{aligned}
$$

Then,

$$
\begin{aligned}
a \| & \left(x_{i+1}^{n}\right)-\left(J\left(x_{i}^{n}\right)+\mu_{n} g_{i}^{n}\left(t_{i}^{n}\right)\right) \|^{q^{\prime}} \\
& \leq V_{*}\left(J^{*}\left(J\left(x_{i+1}^{n}\right)\right), J\left(x_{i}^{n}\right)+\mu_{n} g_{i}^{n}\left(t_{i}^{n}\right)\right) \\
& =V\left(J\left(x_{i}^{n}\right)+\mu_{n} g_{i}^{n}\left(t_{i}^{n}\right), x_{i+1}^{n}\right) \\
& =d_{\Gamma\left(t_{i+1}^{n}, J\left(x_{i}^{n}\right)\right)}^{V}\left(J\left(x_{i}^{n}\right)+\mu_{n} g_{i}^{n}\left(t_{i}^{n}\right)\right) \\
& \leq b\left[d_{\Gamma\left(t_{i+1}^{n}, J\left(x_{i}^{n}\right)\right)}\left(J^{*}\left(J\left(x_{i}^{n}\right)+\mu_{n} g_{i}^{n}\left(t_{i}^{n}\right)\right)\right)\right]^{q} .
\end{aligned}
$$

This inequality with $(66),(73)$, and $\left(H_{6}\right)$, give us

$$
\begin{aligned}
\| J & \left(x_{i+1}^{n}\right)-\left(J\left(x_{i}^{n}\right)+\mu_{n} g_{i}^{n}\left(t_{i}^{n}\right)\right) \| \leq\left(\frac{b}{a}\right)^{1 / q^{\prime}} \\
\cdot & {\left[d_{\Gamma\left(t_{i+1}^{n}, J\left(x_{i}^{n}\right)\right)}\left(J^{*}\left(J\left(x_{i}^{n}\right)+\mu_{n} g_{i}^{n}\left(t_{i}^{n}\right)\right)\right)\right]^{q / q^{\prime}} } \\
= & \left(\frac{b}{a}\right)^{1 / q^{\prime}} \\
\cdot & \left(\left[d_{\Gamma\left(t_{i+1}^{n} J\left(x_{i}^{n}\right)\right)}\left(J^{*}\left(J\left(x_{i}^{n}\right)+\mu_{n} g_{i}^{n}\left(t_{i}^{n}\right)\right)\right)\right]^{q / q^{\prime}}\right. \\
& \left.-\left[d_{\Gamma\left(t_{i}^{n}, J\left(x_{i-1}^{n}\right)\right)}\left(J^{*}\left(J\left(x_{i}^{n}\right)\right)\right)\right]^{q / q^{\prime}}\right) \leq\left(\frac{b}{a}\right)^{1 / q^{\prime}}\left[\gamma_{1} \mu_{n}\right. \\
+ & \gamma_{2}\left\|J\left(x_{i}^{n}\right)-J\left(x_{i-1}^{n}\right)\right\| \\
+ & \left.\gamma_{3}\left\|J^{*}\left(J\left(x_{i}^{n}\right)+\mu_{n} g_{i}^{n}\left(t_{i}^{n}\right)\right)-J^{*}\left(J\left(x_{i}^{n}\right)\right)\right\|\right] .
\end{aligned}
$$

Moreover, from the assumption $q \in(1,2]$, we infer that $q^{\prime} \geq 2$. Then, $E^{*}$ is $q^{\prime}$-uniformly convex $\left(q^{\prime} \geq 2\right)$ and $p^{\prime}$ uniformly smooth. Hence, from Lemma 13, there is a constant $\beta$, depending on $(2 R+T \zeta)$, such that, for all $z_{1}, z_{1} \in E^{*}$, $\left\|z_{1}\right\| \leq 2 R+T \zeta$, and $\left\|z_{2}\right\| \leq 2 R+T \zeta$, we have

$$
\left\|J^{*}\left(z_{1}\right)-J^{*}\left(z_{2}\right)\right\| \leq \beta\left\|z_{1}-z_{2}\right\| .
$$

Consequently,

$$
\begin{aligned}
\| J^{*} & \left(J\left(x_{i}^{n}\right)+\mu_{n} g_{i}^{n}\left(t_{i}^{n}\right)\right)-J^{*}\left(J\left(x_{i}^{n}\right)\right) \| \\
\quad \leq & \beta\left\|J\left(x_{i}^{n}\right)+\mu_{n} g_{i}^{n}\left(t_{i}^{n}\right)-J\left(x_{i}^{n}\right)\right\|=\beta \mu_{n}\left\|g_{i}^{n}\left(t_{i}^{n}\right)\right\| \\
\quad & \beta \mu_{n} \zeta .
\end{aligned}
$$

This inequality and (78) yield

$$
\begin{aligned}
& \left\|J\left(x_{i+1}^{n}\right)-\left(J\left(x_{i}^{n}\right)+\mu_{n} g_{i}^{n}\left(t_{i}^{n}\right)\right)\right\| \\
& \quad \leq\left(\frac{b}{a}\right)^{1 / q^{\prime}}\left[\gamma_{1} \mu_{n}+\gamma_{2}\left\|J\left(x_{i}^{n}\right)-J\left(x_{i-1}^{n}\right)\right\|+\beta \gamma_{3} \mu_{n} \zeta\right] .
\end{aligned}
$$

Thus,

$$
\begin{aligned}
& \left\|J\left(x_{i+1}^{n}\right)-J\left(x_{i}^{n}\right)\right\| \\
& \leq\left(\frac{b}{a}\right)^{1 / q^{\prime}}\left[\gamma_{1} \mu_{n}+\gamma_{2}\left\|J\left(x_{i}^{n}\right)-J\left(x_{i-1}^{n}\right)\right\|+\beta \gamma_{3} \mu_{n}\right] \\
& \quad+\mu_{n} \zeta=\mu_{n}\left(\overline{\gamma_{1}}+\overline{\gamma_{3}}\right)+\overline{\gamma_{2}}\left\|J\left(x_{i}^{n}\right)-J\left(x_{i-1}^{n}\right)\right\|,
\end{aligned}
$$

where $\overline{\gamma_{1}}=(b / a)^{1 / q^{\prime}} \gamma_{1}, \overline{\gamma_{2}}=(b / a)^{1 / q^{\prime}} \gamma_{2}$, and $\overline{\gamma_{3}}=\zeta+$ $(b / a)^{1 / q^{\prime}} \beta \zeta \gamma_{3}$. By repeating the same procedure as $(82),(i-1)$ times, we infer that

$$
\begin{aligned}
& \left\|J\left(x_{i+1}^{n}\right)-J\left(x_{i}^{n}\right)\right\| \\
& \leq \mu_{n}\left(\overline{\gamma_{1}}+\overline{\gamma_{3}}\right)\left[1+\bar{\gamma}_{2}+{\overline{\gamma_{2}}}^{2}+{\overline{\gamma_{2}}}^{3}+\cdots+{\overline{\gamma_{2}}}^{i-1}\right] \\
& \quad+{\overline{\gamma_{2}}}^{i}\left\|J\left(x_{1}^{n}\right)-J\left(x_{0}^{n}\right)\right\| .
\end{aligned}
$$

Note that $\Psi(0) \in \Gamma(0, J(\Psi(0)))$ and $x_{0}^{n}=\Psi(0)$. Then, $x_{0}^{n} \in$ $\Gamma\left(0, J\left(x_{0}^{n}\right)\right)$. Hence, by arguing as in (78) and using (79), one obtains

$$
\begin{aligned}
& \left\|J\left(x_{1}^{n}\right)-\left(J\left(x_{0}^{n}\right)+\mu_{n} g_{0}^{n}\left(t_{0}^{n}\right)\right)\right\|^{q^{\prime}} \leq\left(\frac{b}{a}\right)^{1 / q^{\prime}} \\
& \cdot\left(\left[d_{\Gamma\left(t_{1}^{n}, J\left(x_{0}^{n}\right)\right)}\left(J^{*}\left(J\left(x_{0}^{n}\right)+\mu_{n} g_{0}^{n}\left(t_{0}^{n}\right)\right)\right)\right]^{q / q^{\prime}}\right. \\
& \left.-\left[d_{\Gamma\left(t_{0}^{n}, J\left(x_{0}^{n}\right)\right)}\left(J^{*}\left(J\left(x_{0}^{n}\right)\right)\right)\right]^{q / q^{\prime}}\right)=\left(\frac{b}{a}\right)^{1 / q^{\prime}}\left(\gamma_{1} \mu_{n}\right. \\
& \left.+\gamma_{3}\left\|J^{*}\left(J\left(x_{0}^{n}\right)+\mu_{n} g_{0}^{n}\left(t_{0}^{n}\right)\right)-J^{*}\left(J\left(x_{0}^{n}\right)\right)\right\|\right) \\
& \leq\left(\frac{b}{a}\right)^{1 / q^{\prime}}\left(\gamma_{1} \mu_{n}+\beta \gamma_{3} \mu_{n} \zeta\right) .
\end{aligned}
$$

Thus,

$$
\begin{aligned}
\left\|J\left(x_{1}^{n}\right)-J\left(x_{0}^{n}\right)\right\| & \leq\left(\frac{b}{a}\right)^{1 / q^{\prime}}\left(\gamma_{1} \mu_{n}+\beta \gamma_{3} \mu_{n} \zeta\right)+\mu_{n} \zeta \\
& =\mu_{n}\left(\overline{\gamma_{1}}+\overline{\gamma_{3}}\right) .
\end{aligned}
$$

Relations (83) and (85) and the fact that $0<\gamma_{2}<$ $(a / b)^{1 / q^{\prime}}$ yield

$$
\begin{aligned}
& \left\|J\left(x_{i+1}^{n}\right)-J\left(x_{i}^{n}\right)\right\| \\
& \leq \mu_{n}\left(\overline{\gamma_{1}}+\overline{\gamma_{3}}\right)\left[1+\overline{\gamma_{2}}+{\overline{\gamma_{2}}}^{2}+{\overline{\gamma_{2}}}^{3}+\cdots+{\overline{\gamma_{2}}}^{i-1}+{\overline{\gamma_{2}}}^{i}\right] \\
& \leq \mu_{n}\left(\overline{\gamma_{1}}+\overline{\gamma_{3}}\right) \frac{1}{1-\overline{\gamma_{2}}} .
\end{aligned}
$$


Therefore, for $n \geq 2$, for $i=0,1,2, \ldots, 2^{n}-1$, and for $t \in\left(t_{i}^{n}, t_{i+1}^{n}\right)$, we get

$$
\left\|\left(u_{n}^{*}\right)^{\prime}(t)\right\| \leq\left(\overline{\gamma_{1}}+\overline{\gamma_{3}}\right) \frac{1}{1-\overline{\gamma_{2}}}=\eta .
$$

This shows that (72) is true.

Step 3. We show that there is a Lipschitz function $u^{*}$ : $I \rightarrow E^{*}$, such that the sequence $\left(u_{n}^{*}\right)_{n \geq 2}$ has a convergent uniform subsequence, still denoted by $\left(u_{n}^{*}\right)_{n \geq 2}$, to $u^{*}$ and $\left(u_{n}^{*}\right)_{n \geq 2}^{\prime}$ converges weakly to $\left(u^{*}\right)^{\prime}$.

Indeed, by (72), for any $s_{1}, s_{2} \in I\left(s_{1}<s_{2}\right)$, we have

$$
\left\|u_{n}^{*}\left(s_{1}\right)-u_{n}^{*}\left(s_{2}\right)\right\| \leq \eta\left|s_{1}-s_{2}\right|, \quad \forall n \geq 2 .
$$

Then, the sequence $\left(u_{n}^{*}\right)_{n \geq 2}$ is equicontinuous on $I$. We want to show that, for any $t \in I$, the subset $\left\{u_{n}^{*}(t): n \geq 2\right\}$ is relatively compact in $E^{*}$.

As above, by Lemma 12 , there is a constant $\delta$, depending on $(\|\Psi(0)+T \eta\|)$, such that

$$
\begin{aligned}
& \left\|J^{*}\left(u_{n}^{*}\left(s_{1}\right)\right)-J^{*}\left(u_{n}^{*}\left(s_{2}\right)\right)\right\| \leq \delta\left\|u_{n}^{*}\left(s_{1}\right)-u_{n}^{*}\left(s_{2}\right)\right\| \\
& \quad \leq \delta \eta\left|s_{1}-s_{2}\right|, \quad \forall n \geq 2 .
\end{aligned}
$$

So, for $n \geq 2$ and $t \in I$,

$$
\begin{aligned}
\left\|u_{n}\left(\theta_{n}(t)\right)-u_{n}(t)\right\| & =\left\|J^{*} u_{n}^{*}\left(\theta_{n}(t)\right)-J^{*} u_{n}^{*}(t)\right\| \\
& \leq \delta \eta\left|\theta_{n}(t)-t\right|=\delta \eta \mu_{n} .
\end{aligned}
$$

But, by (66),

$$
u_{n}\left(\theta_{n}(t)\right) \in \Gamma\left(\theta_{n}(t), u_{n}^{*}\left(\delta_{n}(t)\right)\right) .
$$

Then, (90) yields

$$
\begin{aligned}
u_{n}(t) \in & \Gamma\left(\theta_{n}(t), u_{n}^{*}\left(\delta_{n}(t)\right)\right) \\
& +\left\|u_{n}\left(\theta_{n}(t)\right)-u_{n}(t)\right\| B(0,1) \\
\subseteq & \Gamma\left(\theta_{n}(t), u_{n}^{*}\left(\delta_{n}(t)\right)\right)+\delta \eta \mu_{n} B(0,1),
\end{aligned}
$$

$\forall t \in I$.

On the other hand, in view of (88) and $\left(H_{7}\right)$, for any $t \in I$ and any $z \in \Gamma\left(\theta_{n}(t), u_{n}^{*}\left(\delta_{n}(t)\right)\right)$, we have

$$
\begin{aligned}
& {\left[d_{\Gamma\left(t, u_{n}^{*}(t)\right)}(z)\right]^{q / q^{\prime}}} \\
& \quad=\left|\left[d_{\Gamma\left(\theta_{n}(t), u_{n}^{*}\left(\delta_{n}(t)\right)\right)}(z)\right]^{q / q^{\prime}}-\left[d_{\Gamma\left(t, u_{n}^{*}(t)\right)}(z)\right]^{q / q^{\prime}}\right| \\
& \quad \leq \gamma_{1}\left|\theta_{n}(t)-t\right|+\gamma_{2}\left\|u_{n}^{*}\left(\delta_{n}(t)\right)-u_{n}(t)\right\| \\
& \quad \leq \gamma_{1} \mu_{n}+\gamma_{2} \eta\left|\delta_{n}(t)-t\right| \leq \gamma_{1} \mu_{n}+\gamma_{2} \eta \mu_{n} .
\end{aligned}
$$

This means that

$$
\begin{aligned}
\Gamma\left(\theta_{n}(t), u_{n}^{*}\left(\delta_{n}(t)\right)\right) \subseteq & \Gamma\left(t, u_{n}^{*}(t)\right) \\
& +\left(\gamma_{1} \mu_{n}+\gamma_{2} \eta \mu_{n}\right) B(0,1)
\end{aligned}
$$

$\forall t \in I$.
In view of (92) and (94), one obtains

$$
\begin{aligned}
u_{n}(t) & \subseteq \Gamma\left(t, u_{n}^{*}(t)\right)+\left(\delta \eta \mu_{n}+\gamma_{1} \mu_{n}+\gamma_{2} \eta \mu_{n}\right) B(0,1) \\
& =\Gamma\left(t, u_{n}^{*}(t)\right)+\overline{\mu_{n}} B(0,1), \quad \forall t \in I
\end{aligned}
$$

where $\overline{\mu_{n}}=\mu_{n}\left(\delta \eta \mu_{n}+\gamma_{1} \mu_{n}+\gamma_{2} \eta\right)$.

Now, assume by contradiction that there is $t_{0} \in I$ such that $B^{*}\left(t_{0}\right)=\left\{u_{n}^{*}\left(t_{0}\right): n \geq 2\right\}$ is not relatively compact in $E^{*}$. Since $J^{*}$ is continuous on bounded sets, the set $B\left(t_{0}\right)=$ $\left\{u_{n}\left(t_{0}\right): n \geq 2\right\}$ is not relatively compact in $E$. Then, $\chi\left(B\left(t_{0}\right)\right)>0$. Observe that, by (90), for $n \geq 2$,

$$
\begin{aligned}
\left\|u_{n}\left(t_{0}\right)\right\| & =\left\|u_{n}\left(t_{0}\right)-u_{n}(0)\right\|+\|\psi(0)\| \\
& \leq \delta \eta T+\|\psi(0)\|=\bar{\eta} .
\end{aligned}
$$

Therefore, in view of $\left(H_{8}\right)$,

$$
\chi_{E}\left(B\left(t_{0}\right)\right)-\chi_{E}\left(\Gamma\left(t_{0}, B^{*}\left(t_{0}\right)\right) \cap \bar{\eta} B(0,1)\right)>0 .
$$

Then, we can find $\xi>0$ such that

$$
\chi_{E}\left(B\left(t_{0}\right)\right)-\chi_{E}\left(\Gamma\left(t_{0}, B^{*}\left(t_{0}\right)\right) \cap \bar{\eta} B(0,1)\right)>2 \xi .
$$

Let $n_{0}$ be a natural number such that $n_{0} \geq 2$ and $\overline{\mu_{n}}<\xi / 2$, $\forall n \geq n_{0}$. So, by using (95) and (96),

$$
u_{n}\left(t_{0}\right) \subseteq\left(\Gamma\left(t, u_{n_{0}}^{*}(t)\right) \cap \bar{\eta} B\right)+\frac{\xi}{2} B(0,1) .
$$

Then, from the properties of $\chi,(99)$, and $\left(H_{8}\right)$, we infer that

$$
\begin{aligned}
\chi\left(B\left(t_{0}\right)\right) & =\chi\left\{u_{n}\left(t_{0}\right): n \geq n_{0}\right\} \\
& \leq \chi\left(\Gamma\left(t_{0}, B^{*}\left(t_{0}\right)\right) \cap \bar{\eta} B(0,1)\right)+\xi \\
& <\chi\left(B\left(t_{0}\right)\right)-2 \xi+\xi=\chi\left(B\left(t_{0}\right)\right)-\xi
\end{aligned}
$$

which is a contradiction.

Therefore, Theorem 4. Ch.1. in [16] implies that there is a Lipschitz function $u^{*}: I \rightarrow E^{*}$, such that the sequence $\left(u_{n}^{*}\right)_{n \geq 2}$ has a convergent uniform subsequence, still denoted by $\left(u_{n}^{*}\right)_{n \geq 2}$, to $u^{*}$ and $\left(u_{n}^{*}\right)_{n \geq 2}^{\prime}$ converges weakly to $\left(u^{*}\right)^{\prime}$. We extend the definition of $u^{*}$ on $[-r, T]$ by putting $u^{*}(t)=$ $J(\Psi(t)), t \in[-r, 0]$. Thus, $\left(u_{n}^{*}\right)_{n \geq 2}$ converges uniformly to $u^{*}$ on $[-r, T]$. Since $J^{*}$ is uniformly continuous on bounded sets, then the sequence $\left(u_{n}\right)_{n \geq 2}\left(u_{n}=J^{*} u_{n}^{*}\right)$ is uniformly convergent to $u:[-r, T] \rightarrow E$ with $u=J^{*}\left(u^{*}\right)$.

Step 4. Let us show that $u(t) \in \Gamma\left(t, u^{*}(t)\right), t \in I$.

Let $t \in I$. According to $\left(H_{7}\right)$, we have

$$
\begin{aligned}
& {\left[d_{\Gamma\left(t, u^{*}(t)\right)}(u(t))\right]^{q / q^{\prime}}=\mid\left[d_{\Gamma\left(t, u^{*}(t)\right)}(u(t))\right]^{q / q^{\prime}}} \\
& -\left[d_{\Gamma\left(\theta_{n}(t), u^{*}\left(\delta_{n}(t)\right)\right)}\left(u_{n}\left(\theta_{n}(t)\right)\right)\right]^{q / q^{\prime}}\left|\leq \gamma_{1}\right| \theta_{n}(t) \\
& \quad-t \mid+\gamma_{2}\left\|u^{*}(t)-u_{n}^{*}\left(\delta_{n}(t)\right)\right\|+\gamma_{3} \| u(t) \\
& \quad-u_{n}\left(\theta_{n}(t)\right) \| .
\end{aligned}
$$


Note that $\lim _{n \rightarrow \infty} \gamma_{1}\left|\theta_{n}(t)-t\right|+\gamma_{2}\left\|u^{*}(t)-u_{n}^{*}\left(\delta_{n}(t)\right)\right\|+$ $\gamma_{3}\left\|u(t)-u_{n}\left(\theta_{n}(t)\right)\right\|=0$. Then, $u(t) \in \Gamma\left(t, u^{*}(t)\right), t \in I$.

Step 5. Following the same lines in Steps 5 and 6 in the proof of Theorem 15, we can show that $\lim _{n \rightarrow \infty} \| \tau\left(\delta_{n}(t)\right) u_{n}-$ $\tau(t) u \|_{C_{E}([-r, 0])}=0$, for every $t \in I$. Moreover, the sequence $\left(f_{n}\right)_{n \geq 2}$ defined by $f_{n}(t)=g_{n}\left(\delta_{n}(t)\right), t \in I$, converges almost everywhere to a function $f \in L^{1}\left(1, E^{*}\right)$ and $f(t) \in$ $F(t, \tau(t) u)$, a.e. $t \in I$.

Step 6. We proceed to show that

$$
-(J u)^{\prime}(t)+f(t) \in N_{\Gamma\left(t, u^{*}(t)\right)} u(t), \quad \text { a.e. } t \in I .
$$

In view of (72) and (73) and Lemma 11, for every natural number $n \geq 2$, one obtains

$$
\begin{aligned}
- & \left(J u_{n}\right)^{\prime}(t)+f_{n}(t) \\
& \in(\eta+\varsigma) \partial d_{\Gamma\left(\theta_{n}(t), u^{*}\left(\delta_{n}(t)\right)\right)}\left(u_{n}\left(\theta_{n} t\right)\right), \quad \text { a.e. } t \in I .
\end{aligned}
$$

By $\left(\mathrm{H}_{2}\right)$ and ([19], Prop. 1.7), the multivalued function $(t, y) \rightarrow \partial d_{\Gamma(t)}(y)$ is scalary uppersemicontinuous with convex and weak ${ }^{*}$ compact values. Then, for any $v \in E$,

$$
\begin{aligned}
& \limsup _{n \rightarrow \infty} \sigma\left(v, \partial d_{\Gamma\left(\theta_{n}(t), u^{*}\left(\delta_{n}(t)\right)\right)}\left(u_{n}\left(\theta_{n} t\right)\right)\right) \\
& \quad \leq \sigma\left(v, \partial d_{\Gamma\left(t, u^{*}(t)\right)}(u(t))\right),
\end{aligned}
$$

where $\sigma$ is the support function.

Now, let $\left(e_{k}\right)$ be a sequence in $E$ which separates the points. Hence, from the weak convergence of the sequence $\left(\left(J u_{n}\right)^{\prime}+f_{n}\right)_{n \geq 2}$ to $J\left(u^{\prime}\right)+f$ in $L^{1}\left(I, E^{*}\right)$, for any Lebesgue measurable subset $A \subseteq I$, we have

$$
\begin{aligned}
\int_{A} & \left\langle e_{k},\left(-(J u)^{\prime}(t)+f(t)\right)\right\rangle d t \\
& =\lim _{n \rightarrow \infty} \int_{A}\left\langle e_{k},\left(-\left(J u_{n}\right)^{\prime}(t)+f_{n}(t)\right)\right\rangle d t .
\end{aligned}
$$

This relation with (103) and (104) yields

$$
\begin{aligned}
& \int_{A}\left\langle e_{k},\left(-(J u)^{\prime}(t)+f(t)\right)\right\rangle d t \leq \limsup _{n \rightarrow \infty} \int_{A} \sigma\left(e_{k}\right. \\
& \left.(\eta+\varsigma) \partial d_{\Gamma\left(\theta_{n}(t), u^{*}\left(\delta_{n}(t)\right)\right)}\left(u_{n}\left(\theta_{n} t\right)\right)\right) d t \\
& \leq \int_{A} \limsup _{n \rightarrow \infty} \sigma\left(e_{k},\right. \\
& \left.(\eta+\varsigma) \partial d_{\Gamma\left(\theta_{n}(t), u^{*}\left(\delta_{n}(t)\right)\right)}\left(u_{n}\left(\theta_{n} t\right)\right)\right) d t \\
& \leq \int_{A} \sigma\left(v, \partial d_{\Gamma\left(t, u^{*}(t)\right)}(u(t))\right) d t
\end{aligned}
$$

So, for almost $t \in I$,

$$
\left\langle e_{k},\left(-(J u)^{\prime}(t)+f(t)\right)\right\rangle \leq \sigma\left(v, \partial d_{\Gamma\left(t, u^{*}(t)\right)}(u(t))\right),
$$$$
\forall k \geq 1
$$

Again, since the multivalued function $t \rightarrow \partial d_{\Gamma(t)}(u(t))$ is measurable with convex and weak ${ }^{*}$ compact, then by $([18]$, III.35) it follows that

$$
-(J u)^{\prime}(t)+f(t) \in(\eta+\varsigma) \partial d_{\Gamma\left(t, u^{*}(t)\right)}(u(t)), \quad \text { a.e. }
$$

As $u(t) \in \Gamma\left(t, u^{*}(t)\right), \forall t \in I$, we get

$$
-(J u)^{\prime}(t)+f(t) \in N_{\Gamma\left(t, u^{*}(t)\right)}(u(t)), \quad \text { a.e. }
$$

This completes the proof.

\section{Conflict of Interests}

The authors declare that there is no conflict of interests regarding the publication of this paper.

\section{Acknowledgment}

The authors gratefully acknowledge the Deanship of Scientific Research, King Faisal University of Saudi Arabia, for their financial support for this Research Project no. 150153.

\section{References}

[1] J. J. Moreau, "Evolution problem associated with a moving convex set in a Hilbert space," Journal of Differential Equations, vol. 26, no. 3, pp. 347-374, 1977.

[2] M. Aitalioubrahim, "On noncompact perturbation of nonconvex sweeping process," Commentationes Mathematicae Universitatis Carolinae, vol. 53, no. 1, pp. 65-77, 2012.

[3] F. A. Al-Adsani and A. G. Ibrahim, "Noncompact perturbation of sweeping process with delay in Banach spaces," International Journal of Mathematics and Mathematical Sciences, vol. 2013, Article ID 567094, 10 pages, 2013.

[4] M. Bounkhel and L. Thibault, "Non-convex sweeping process and prox-regular in Hilbert spaces," Journal of Nonlinear and Convex Analysis, vol. 6, pp. 359-374, 2005.

[5] M. Bounkhel and R. Al-Yusof, "First and second order convex sweeping processes in reflexive smooth banach spaces," SetValued and Variational Analysis, vol. 18, no. 2, pp. 151-182, 2010.

[6] M. Bounkhel and C. Castaing, "State dependent sweeping process in $p$-uniformly smooth and $q$-uniformly convex Banach spaces," Set-Valued and Variational Analysis, vol. 20, no. 2, pp. 187-201, 2012.

[7] A. G. Ibrahim and F. A. AL-Adsani, "Second order evolutions inclusions governed by sweeping process in Banach spaces," Le Matematiche, vol. 64, no. 2, pp. 17-39, 2009.

[8] J. Noel and L. Thibault, "Nonconvex sweeping process with a moving set depending on the state," Vietnam Journal of Mathematics, vol. 42, no. 4, pp. 595-612, 2014.

[9] L. Thibault, "Sweeping process with regular and nonregular sets," Journal of Differential Equations, vol. 193, no. 1, pp. 1-26, 2003.

[10] C. Castaing, A. G. Ibrahim, and M. Yarou, "Some contributions to nonconvex sweeping process," Journal of Nonlinear and Convex Analysis, vol. 10, no. 1, pp. 1-20, 2009.

[11] A. M. Gomaa, "Relaxation problems involving second order differential inclusions," Abstract and Applied Analysis, vol. 2013, Article ID 792431, 9 pages, 2013. 
[12] Y. I. Alber, "Generalized projection operators in Banach spaces: properties and applications," Functional Differential Equations, vol. 1, pp. 1-21, 1994.

[13] W. Takahashi, Nonlinear Functional Analysis, Yokohama Publishers, 2000.

[14] R. Deville, G. Godefroy, and V. Zizler, Smoothness and Renormings in Branch Spaces, Pitman Monographs and Surveys in Pure and Applied Mathematics, Longman Scientific \& Technical, Harlow, UK, 1993.

[15] Q. J. Zhu, "On the solution set of differential inclusions in Banach space," Journal of Differential Equations, vol. 93, no. 2, pp. 213-237, 1991.

[16] J. P. Aubin and A. Cellina, Differential Inclusions: Set-Valued Maps and Viability Theory, Springer, Berlin, Germany, 1984.

[17] L. Thibault, Propriétés des sous-différentiels de fonctions localement lipschitziennes définies sur un espace de Banach séparable. Applications [Ph.D. thesis], University of Montpellier, Montpellier, France, 1976.

[18] C. Castaing and M. Valadier, Convex Analysis and Measurable Multifunctions, vol. 580 of Lecture Notes in Mathematics, Springer, Berlin, Germany, 1977.

[19] L. Thibault, "Requalarization of non-convex sweeping process in Hilbert spaces," Set-Valued Analysis, vol. 16, no. 23, pp. 319333,2008 . 


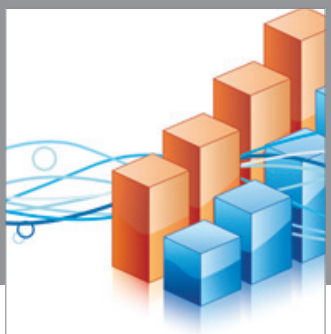

Advances in

Operations Research

vatem alat4

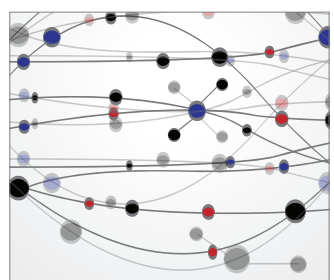

\section{The Scientific} World Journal
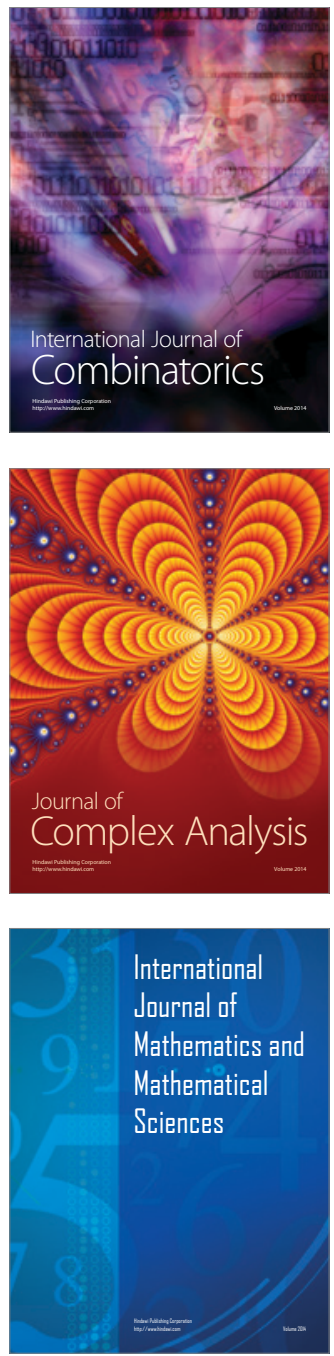
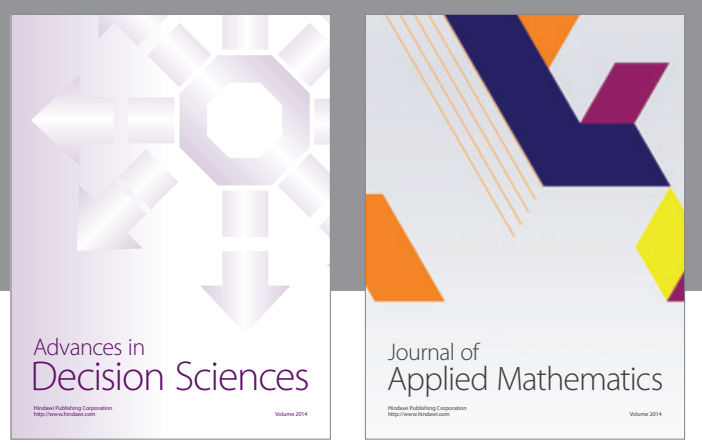

Algebra

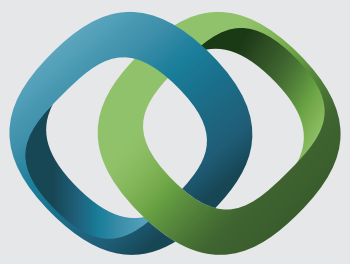

\section{Hindawi}

Submit your manuscripts at

http://www.hindawi.com
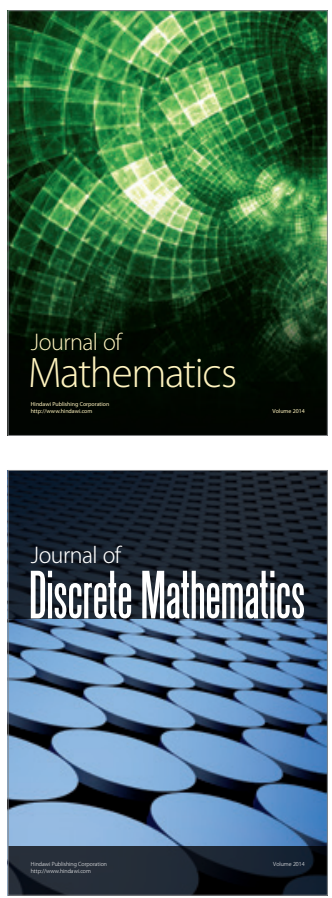

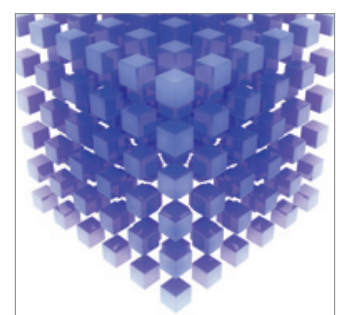

Mathematical Problems in Engineering
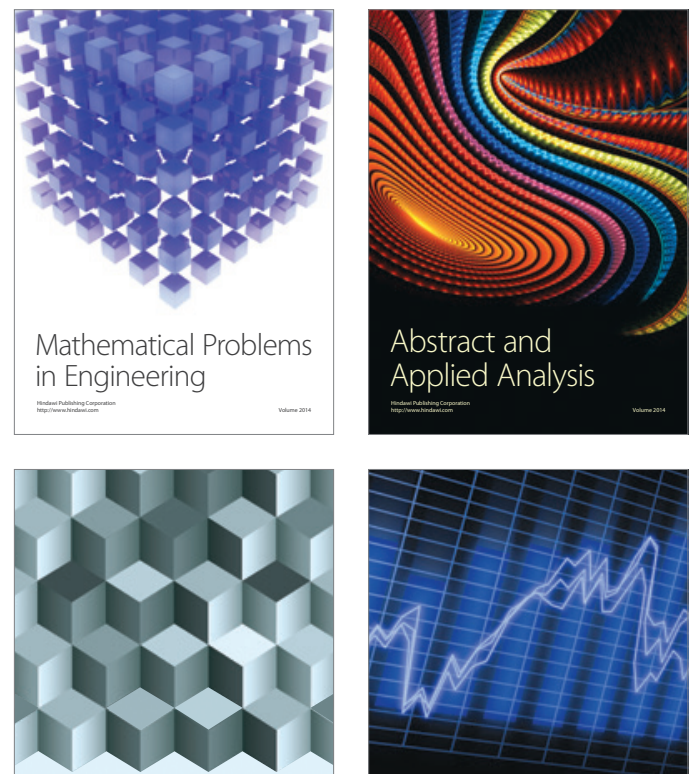

Journal of

Function Spaces

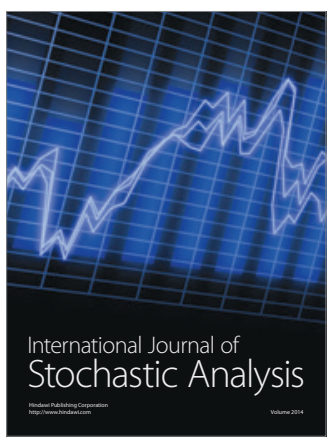

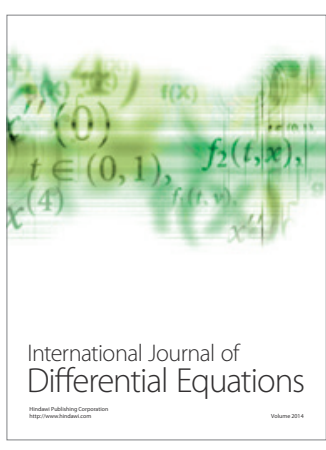
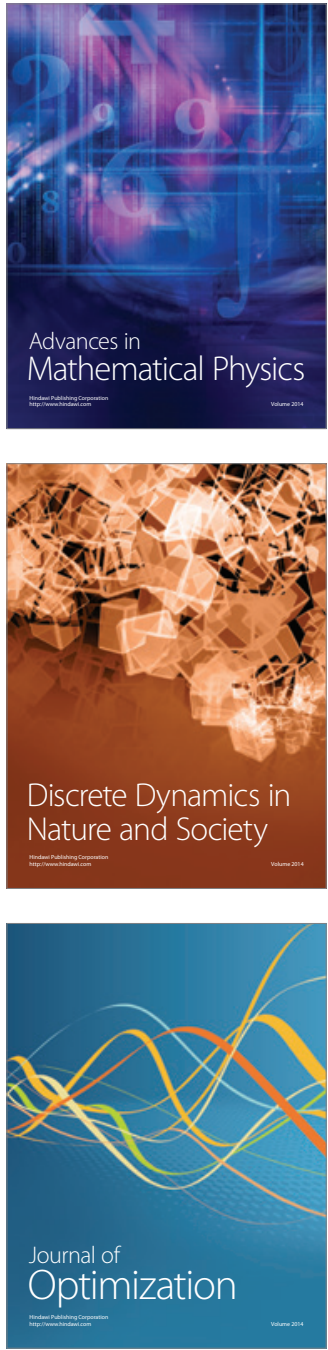